\title{
Expectancy Influences on Attention to Threat Are Only Weak and Transient: Behavioral and
}

\section{Physiological Evidence}

Running Head: Expectancy Influences on Attention to Threat

Tatjana Aue ${ }^{\mathrm{a}, \mathrm{b}^{*}}$, Léa A. S. Chauvignéc ${ }^{\text {, }}$ Mirko Bristle $^{\mathrm{a}}$, Hadas Okon-Singer ${ }^{\mathrm{d}}$, and Raphaël Guex ${ }^{\mathrm{b}, \mathrm{e}}$

\author{
${ }^{a}$ Institute of Psychology, University of Bern, Switzerland \\ ${ }^{\mathrm{b}}$ Swiss Center for Affective Sciences, University of Geneva, Switzerland \\ ${ }^{\mathrm{c}}$ Department of Psychology, McMaster University, Hamilton, Canada \\ ${ }^{\mathrm{d}}$ Department of Psychology, University of Haifa, Israel \\ e Department of Psychology, University of Geneva, Switzerland
}

Number of figures: 5

Number of tables: 4

\section{*Correspondence:}

Tatjana Aue

University of Bern

Institute of Psychology

Division of Experimental Psychology and Neuropsychology

Fabrikstr. 8

3012 Bern

Switzerland

tatjana.aue@psy.unibe.ch

Phone: +41316314095 


\begin{abstract}
Can prior expectancies shape attention to threat? To answer this question, we manipulated the expectancies of spider phobics and nonfearful controls regarding the appearance of spider and bird targets in a visual search task. We observed robust evidence for expectancy influences on attention to birds, reflected in error rates, reaction times, pupil diameter, and heart rate (HR). We found no solid effect, however, of the same expectancies on attention to spiders; only HR revealed a weak and transient impact of prior expectancies on the orientation of attention to threat. Moreover, these asymmetric effects for spiders versus birds were observed in both phobics and controls. Our results are thus consistent with the notion of a threat detection mechanism that is only partially permeable to current expectancies, thereby increasing chances of survival in situations that are mistakenly perceived as safe.
\end{abstract}

Keywords: encounter expectancy bias; attention bias; combined cognitive biases hypothesis; fear module; biological preparedness; spider phobia; pupil diameter; heart rate; respiration rate; visual search 


\section{Expectancy Influences on Attention to Threat Are Only Weak and Transient: Behavioral and}

\section{Physiological Evidence}

Cognitive biases have been observed in both clinical and subclinical fear (Aue \& Okon-Singer, 2015; Hirsch, Clark, \& Mathews, 2006; Mathews, Mackintosh, \& Fulcher, 1997), while their existence in healthy individuals is more heavily debated (e.g., Bar-Haim, Lamy, Pergamin, Bakermans-Kranenburg, \& van IJzendorn, 2007). Several of these biases, including those in attention and expectancies, have been suggested to provoke and maintain anxiety disorders (Butler \& Mathews, 1983; Taylor \& Rachman, 1994). Systematic investigations of the biases and their interactions may yield a better understanding of the neurocognitive mechanisms underlying different types of fear, which is an important precondition for the development of adequate treatments. Following our earlier research on the topic (e.g., Aue, Guex, Chauvigné, \& OkonSinger, 2013), here we further investigate the question of whether — and to what extent — biased expectancies might cause biases in attention to threat.

Cisler and Koster (2010) classify threat-related biases in attention as (a) early automatic vigilance for threat (Mogg \& Bradley, 1998), termed facilitated attention (hereafter referred to as vigilance); (b) difficulty in disengaging attention from threat once it has been oriented to (Fox, Russo, Bowles, \& Dutton, 2001; Fox, Russo, \& Dutton, 2002; Yiend \& Mathews, 2001); and (c) attentional avoidance of threat (Amir, Foa, \& Coles, 1998; Mogg, Bradley, DeBono, \& Painter, 1997). The authors relate these different types of attention bias to different information processing stages. Specifically, vigilance to threat is seen as a result of automatic processing particularities arising from the initiation of an innate threat detection mechanism centered around the amygdala. Difficulty in disengagement of attention from threat, in contrast, is considered to be related to a mixture of strategic and automatic processing deficits that reflect defective attentional control mediated by the prefrontal cortex. Attentional avoidance of threat, finally, is thought to result from strategic processing peculiarities associated with the regulation of negative emotion that is also mediated by the prefrontal cortex. 
Such a distinction of attention bias components can possibly explain some seemingly discrepant findings in the literature (e.g., phobia being characterized by vigilance to threat vs. avoidance of threat). For instance, in phobia, problems arising during early automatic processing of a threatening situation may temporarily lead to hypervigilance, whereas deficits during later strategic processing may be reflected in visual avoidance, corresponding to the so-called vigilanceavoidance pattern (cf. Amir et al., 1998, and Mogg et al., 1997, for supportive evidence). Yet, there are also counterexamples to the vigilance-avoidance pattern idea in pathological fear. For instance, some authors find no evidence for vigilance to threat during automatic information processing and report only attentional avoidance during strategic information processing (e.g., Aue, Hoeppli, Piguet, Sterpenich, \& Vuilleumier, 2013; Hermans, Vansteenwegen, \& Eelen, 1999). These inconsistencies remain to be resolved by future research.

Much can be learned from the identification of the concrete factors that cause vigilance and avoidance. One of these influential factors might relate to prior expectancies that, at times, are themselves biased. Indeed, expectancy biases are common in exaggerated fear and phobia (Aue \& Hoeppli, 2012; Foa \& Kozak, 1986). For example, spider phobics have been reported to overassociate spiders with negative outcomes (consequences expectancy bias; e.g., Mühlberger, Wiedemann, Herrmann, \& Pauli, 2006; Muris, Huijding, Mayer, den Breejen, \& Makkelie, 2007). Furthermore, spider phobics, but not nonfearful controls, overestimate the likelihood of encountering spiders (encounter expectancy bias; e.g., Aue \& Hoeppli, 2012; Aue et al., 2015; de Jong \& Muris, 2002). Comparable biases have been reported for other anxiety disorders (Amrhein, Pauli, Dengler, \& Wiedemann, 2005; Foa, Franklin, Perry, \& Herbert, 1996; McManus, Clark, \& Hackmann, 2000).

Given the prevalent nature of both attention and expectancy biases in anxiety disorders, it is imaginable that one type of bias originates in the other. For instance, because highly fearful and phobic individuals overestimate the likelihood of being confronted with situations they fear (i.e., encounter expectancy bias), they may subsequently modify their deployment of attention. In some cases, such as a likely attack by a predator, it may be adaptive to be particularly vigilant; increased 
vigilance may ultimately result in facilitated detection of the threat source. Combined with an expectancy-triggered preparation of adequate behavioral responses that enable quick distancing from the anticipated source of threat, facilitated detection may thus save time that is essential to survival. However, if flight is determined to be nonessential for survival, highly fearful and phobic individuals may ultimately engage in visual avoidance of the threat source in order to successfully regulate their fear. Whether sustained vigilance or avoidance arises from enhanced encounter expectancies may thus depend on the moment in time and/or the type of anticipated consequences (i.e., consequences expectancy bias).

One may also hypothesize about the existence of the reverse link, namely, that attention deployment has a causal impact on expectancies. Focusing on negative aspects in a situation may increase the subjective likelihood of similarly negative things happening in the future, simply because people base their appreciation of the future on available information. These reflections suggest that expectancies and attentional processes may be intimately linked in pathological fear, with one bias causing the other. In fact, the "combined cognitive biases hypothesis" (Hirsch et al., 2006; see also Everaert, Koster, \& Derakshan, 2012; Ingram, 1984; J. M. G. Williams, Watts, MacLeod, \& Mathews, 1997) states that cognitive biases in psychopathology rarely operate independently but, rather, most often mutually influence each other. Along these lines, Peschard and Philippot (2015) suggested attentional and memory processes in anxiety to be closely connected. According to these authors, it is the focus of attention that determines awareness of working memory content, and the focus of attention should itself be influenced by factors such as task goals, stimulus salience, and long-term memory.

Theoretical considerations raised by researchers in the tradition of the combined cognitive biases hypothesis (e.g., Everaert et al., 2012; Hirsch et al., 2006) comprise memory, interpretation, and attention biases, as well as self-imagery bias. We (Aue \& Okon-Singer, 2015) recently proposed that this theoretical perspective can be easily broadened to include expectancy biases. The identification of mutual influences between different types of cognitive bias (e.g., attention bias, 
expectancy bias, interpretation bias, memory bias) is thought to have an important impact on the understanding of the basic mechanisms underlying anxiety disorders and might inspire the development of new, more efficient, therapeutic approaches that straightforwardly address the causal factors. Yet, to date, studies examining (causal) relations between attention and expectancy biases are surprisingly sparse.

In two experiments, we investigated the nature of the relationship between attention and expectancies. An eye-tracking experiment (Aue, Hoeppli, et al., 2013) revealed that self-determined visual avoidance of depicted spiders in spider phobics during strategic information processing was associated with a reduced subsequently indicated encounter expectancy bias in these individuals (i.e., the less attention that was paid to a picture of a spider, the lower the subjective likelihood of encountering the animal displayed). Hence, visual avoidance in phobic fear may be hypothesized to downregulate encounter expectancies and thereby to possibly downregulate experienced fear. Interestingly, the opposite relationship was observed for the control group, which was characterized by low spider fear: These participants showed a positive correlation between the extent of visual avoidance of the spiders and their encounter expectancies for spiders. Therefore, healthy participants may be better at regulating their expectancies (and fear) if they are particularly attentive to potentially menacing situations. Yet, because our experimental paradigm did not allow the investigation of causality, these interpretations of the data are to be treated with reservation.

In a second study, we (Aue, Guex, et al., 2013) directly examined causality in the expectancy-attention relationship. To measure vigilance to threat in spider phobic and nonfearful controls, we used a visual search task (Flykt, Lindeberg, \& Derakshan, 2012; Öhman, Flykt, \& Esteves, 2001; Soares, Esteves, Lundqvist, \& Öhman, 2009). Participants saw a 3 (rows) $\times 3$ (columns) search array, their task being to rapidly detect a spider or a bird target displayed among eight butterflies (distractors). Vigilance to threat was assessed by comparing the participants' reaction times (RTs) for the detection of spider versus bird targets. 
To test whether prior expectancies exert a causal influence on vigilance to threat, we manipulated encounter expectancies; verbal cues preinformed the participants about the likelihood that the target in the subsequently displayed visual search array would be a spider or a bird. Because expectancies were hypothesized to effectuate a top-down influence on early attention deployment in the visual search task, we had predicted an effect of congruency, with detection of spider targets being facilitated by spider cues and detection of bird targets being facilitated by bird cues. ${ }^{1}$

Surprisingly, though, the RTs of neither the spider phobic nor the control participants revealed an influence of the expectancy cues on the detection of spider targets. Notably, the same expectancy cues clearly had the predicted impact on RTs for bird targets, thus providing evidence that our expectancy manipulation had been successful. Together, therefore, these RT data did not yield support to our idea that expectancy bias is at the origin of attention bias for threat. Instead, we discussed the possibility that evolution has formed attentional systems that are specific to the detection of phylogenetic threat (e.g., Öhman \& Mineka, 2001; Seligman, 1971) and that are only weakly or not at all susceptible to expectancies. In fact, the existence of a fear module (Davis \& Lang, 2003; LeDoux \& Phelps, 2000; Öhman \& Mineka, 2001) that ensures automatic processing of threatening stimuli (cf. Cisler \& Koster, 2010) independently of explicit expectancies may be advantageous for survival; after all, false expectancies of safety may have fatal consequences.

Yet, these data do not necessarily imply that expectancies have been altogether irrelevant for the detection of spider targets. The influence of expectancies on attention deployment could be subject to temporal unfolding and thus different at different moments in time. One possible scenario is that humans do detect expected spiders earlier than unexpected spiders. Because unexpected detection of spider targets may signal greater urgency than expected detection of those targets, attention allocation after detection may, however, be temporarily intensified for the unexpected spider targets (reorienting of attention), and subsequent translation into overt behavior (i.e., target indication in the visual search task) may be speeded up. Thus, the lack of influence of expectancies on attention as revealed in the RTs of our earlier study could be due to unexpected spider targets 
calling for particularly fast behavioral responding. Speeded responding would enable an individual to make up for the initial delay that arose from false expectancy.

But even in the case that expectancies do not influence the detection of spiders, (dis)confirmation of expectancies might still play a role in attention allocation and response preparation later on. For instance, registration of deviation with expectations could lead the organism to quickly respond with corrective physiological changes (e.g., related to the reorienting of attention) in order to adequately process and adaptively confront the situation. ${ }^{2}$ Together, these reflections show that temporal processing differences between expected and unexpected spider targets might cancel each other out in RTs. Unlike time-sensitive physiological measures such as pupil diameter and heart rate (HR), RTs would not adequately map such temporal unfolding in attention allocation, especially if the corresponding changes were only weak. Thus, there might be measures that are more sensitive than RTs that still reveal an influence of expectancy on attention to threat.

To investigate this question further, we conducted a new study based on the same experimental paradigm. In addition to RTs and error rates in the visual search task, we measured our participants' pupil diameter, HR, and respiration rate (RR). We examined how attention bias and, most important, the influence of prior expectancies on attention to threatening versus nonthreatening targets, are reflected in behavior and physiology.

First, we expected an attention bias for spider targets, especially in phobics (cf. Bar-Haim et al., 2007; Okon-Singer, Lichtenstein-Vidne, \& Cohen, 2013). Greater vigilance for spider rather than bird targets was predicted to be reflected in fewer errors and shorter RTs. Moreover, in the literature, orienting of attention has been related to increased pupil diameter (Lynn, 1966; Sokolov, 1963; Wang \& Munoz, 2015, but see Steiner \& Barry, 2011) and decreased early HR (Bradley \& Lang, 2007; Stekelenburg \& Van Boxtel, 2002) and suggested to increase sensory sensitivity. Accordingly, we predicted a greater pupil diameter and more pronounced initial HR deceleration for 
spider than for bird targets. Usually, HR in response to the presentation of visual scenes is characterized by a triphasic pattern (initial deceleration followed by acceleration followed by second deceleration; e.g., Lang, Bradley, \& Cuthbert, 1997). In addition to the initial decrease in HR, we anticipated a greater subsequent HR acceleration (corresponding to greater mobilization after target detection; Aue, Hoeppli, \& Piguet, 2012; Flykt, 2005; Flykt et al., 2012) for spider than for bird targets.

Second, from the results of our earlier study, we predicted the effect of cue-target congruency for bird targets to be visible in our participants' behavior (response errors and RTs). Specifically, identification of bird targets was hypothesized to be facilitated by bird cues and slowed down by spider cues. By contrast, cue-target congruency was expected to be absent regarding behavioral indicators (i.e., response errors and RTs) of the identification of spider targets. Moreover, we hypothesized that, in contrast to the behavioral responses, our participants' physiology regarding spider targets would be influenced by the earlier presented cues. Specifically, we hypothesized that, because of reorienting of attention, the processing of unexpected targets (comprising both spiders and birds) would rely on greater attentional resources, expressed in increased pupil diameter and stronger initial HR deceleration (see Supplementary Materials for additional hypotheses regarding RR).

\section{Methods}

\section{Participants}

Forty-five participants (21 spider phobic; 10 male [4 in the spider phobic and 6 in the control group]), aged between 18 and 34 years $(M=23.5, S D=4.10)$ were recruited via ads placed in university buildings, as well as on university and local websites. The study was embedded in a larger project investigating decision making and psychophysiological responses during the imagination of encounters with feared and nonfeared animals. The ads explicitly specified these project aims. Persons interested in the study were interviewed by telephone and checked for criteria 
of the Diagnostic and Statistical Manual of Mental Disorders (4th ed., text rev.; DSM-IV; American Psychiatric Association, 2000) and the International Statistical Classification of Diseases and Related Health Problems (10th rev.; ICD-10; World Health Organization; 1992) for the presence or absence of spider phobia (adapted from Mühlberger et al., 2006). Participants were included in the study if they (a) met the DSM-IV and $I C D-10$ criteria for spider phobia (spider phobic group), or (b) fulfilled none of the criteria and additionally claimed to not fear spiders (control group). Another condition for inclusion in the study was a body mass index between 18.5 and 25 . Exclusion criteria comprised neurological, cardiovascular, respiratory, and psychiatric diseases other than spider phobia, as well as medication use, pregnancy, claustrophobia, and metal implants. Some of these criteria related to the fact that participants performed the experimental task in a magnetic resonance imaging (MRI) scanner (functional MRI data are not presented here and have not been published yet).

Fear of spiders was further assessed after the experiment with the French translation of the Fear of Spiders Questionnaire (Szymanski \& O’Donohue, 1995), t(43) $=14.40, p<.000001(M \mathrm{~s}=$ 89.6 and 28.9, $S D \mathrm{~s}=15.05$ and 13.20, for phobic and control groups, respectively). Participants in the two groups did not differ with respect to age, $t(43)=-0.93, n s(M \mathrm{~s}=22.9$ and 24.0 years, $S D \mathrm{~s}=$ 3.61 and 4.50 years, for phobic and control groups, respectively); trait anxiety, $t(43)=0.67, n s$ (Ms $=40.9$ and 39.1, SDs $=8.31$ and 8.93, for phobic and control groups, respectively); and state anxiety, $t(42)=1.25, n s(M \mathrm{~s}=35.3$ and $31.9, S D s=9.45$ and 10.23 , for phobic and control groups, respectively; one participant in the control group did not complete this scale), as measured with the French version (Gauthier \& Bouchard, 1993) of the State-Trait Anxiety Inventory (original English version: Spielberger, 1983).

\section{Stimuli and Experimental Paradigm}


The experimental task was a visual search task and included the presentation of three types of expectancy cues that were thought to facilitate or inhibit the detection of spider and bird targets in a search array (see Procedure for further details).

Cues (expectancy manipulation). Three types of verbal cues were presented as text on the computer screen. The first, "spider $90 \%$," specified a $90 \%$ probability that the to-be-detected (deviant) target in the subsequently presented search array would be a spider among eight butterflies. Because the target could have been either a spider or a bird, this cue expressed a high probability for a spider target and a low probability for a bird target. The second cue, "bird 90\%," specified a $90 \%$ probability that the to-be-detected target in the subsequently presented search array would be a bird. Thus, this cue expressed a high probability for a bird target and a low probability for a spider target. Finally, the third cue, "spider bird 50\%" (for half of the participants; for the other half, the third cue was "bird spider 50\%"), specified an equal probability for a spider or a bird to be the target in the search array and constituted a control condition with maximum uncertainty. In such cases, habitual individual response tendencies (related to habitual encounter expectancies) might be strongest.

In reality, the spider $90 \%$ [bird 90\%] cue (for simplicity, termed spider [bird] cue in the following) condition referred to a probability of $70 \%$ (68 trials) that there would actually be a spider [bird] target among eight butterflies in the search array presented thereafter. This discrepancy occurred because we had aimed at reducing the duration of the experiment while keeping the cues highly salient and ensuring enough trials in each experimental condition; refer to the Limitations section for details. In the remaining cases, either a bird [spider] target was presented ( 24 trials) or no deviant at all (4 trials). The latter trials were included to verify that the participants responded on the basis of target perception. 
In the $50 \%$ (i.e., ambiguous) cue condition, in contrast, there was indeed an equal likelihood of either a spider or a bird being the target in the subsequently shown search array (48 trials; 24 spider targets and 24 bird targets). In some cases, there was no deviant (4 trials).

Visual search array (used to measure vigilance). Stimuli consisted of (a) 30 pictures displaying spiders, all taken from the Geneva Affective PicturE Database (GAPED; Dan Glauser \& Scherer, 2011); (b) 30 birds, collected from the Internet; and (c) 100 butterflies, also collected from the Internet. The animals covered virtually the whole picture (see example of a search array in Figure 1). In each trial, the search array consisted of a matrix of nine different animal pictures with three columns and three rows. There was no space in-between the pictures, and each picture within the matrix was displayed at $341 \times 256$ pixels. The butterfly distracters were selected on the basis of the assumption that they share significant features with both spiders and birds (e.g., wings corresponding to birds' wings; six legs and two antennas corresponding to the eight legs of spiders). Seventy-five percent of the butterflies were displayed from their side, clearly showing all legs and antennas. All images were displayed in gray scale, preventing pop-out effects based on color differences between stimulus categories. The stimuli in the two categories were matched for luminance and contrast, and spider and bird targets appeared with an equal probability in any of the nine different locations within the matrix.

\section{Procedure}

Upon participants' arrival at the laboratory, the nature of the experiment was explained and written informed consent was obtained (protocol approved by the local ethics committee and in accordance with the Helsinki Declaration of Human Rights; World Medical Association, 1999). The experimental task was introduced as a test of the capacity to detect spiders and birds in an array of butterflies and performed in an MRI scanner (MRI data are not presented here). After participants had thoroughly read the instructions for the task, they performed 10 practice trials to become familiar with the task. If they had no questions, they were comfortably positioned in an MRI 
scanner and the physiological sensors that enabled the acquisition of HR and RR were attached. Before starting with the experimental task, a standard calibration procedure for eye tracking (in order to permit acquisition of pupil diameter) was undertaken. During this procedure, participants looked at nine dots appearing at different locations on the computer screen. The experimental task was performed next.

In each experimental trial, participants saw a fixation cross that was followed by a cue. The cue referred to the probability that the to-be-detected target in the subsequently presented search array would be a spider or a bird (see preceding section for details). After the presentation of the cue, another fixation cross appeared. Next, the search array consisting of nine pictures (either nine butterflies [no target], eight butterflies and a spider, or eight butterflies and a bird) was shown and the participants had to decide whether there was no target, or whether the target was a spider or a bird.

Participants were instructed to react as fast and as correctly as possible. Responses were given by pressing three different buttons of a response button box (counterbalanced across participants). In total, 244 experimental trials were presented in random order in four runs of 61 trials with short pauses in between. The average intertrial interval was $9.5 \mathrm{~s}$ (range: 9-10 s; for an example of an experimental trial [task sequence], see Figure 1). We decided on such a comparably long intertrial interval (i.e., long experimental trials) for two reasons: First, we attempted to ensure enough time to allow long latency signals (e.g., RR) to unfold in response to the different cues and targets and, second, we wanted to provide sufficient time for cue processing (on average $4 \mathrm{~s}$ ), thus permitting our participants to prepare a search strategy. After the participants had completed the Fear of Spiders Questionnaire and the trait and state scales of the State-Trait Anxiety Inventory, they were debriefed.

\section{Setting and Apparatus}


HR was acquired continuously at a sampling rate of $10000 \mathrm{~Hz}$ with the Biopac MP150 System (Goleta, CA, USA). HR (in beats per minute, bpm) was assessed by the use of the TSD123 oximeter transducer placed on the participant's index finger. Peripheral signals were transferred from the experimental room to the MP150 Acquisition Unit (16-bit A/D conversion) in the control room and stored on computer hard disk. A digital channel received inputs from the presentation computer and recorded on- and offset of the presented stimuli. Parameterization was performed with AcqKnowledge 4.1 (Biopac, Goleta, CA, USA).

Visual stimuli were presented on a back projection screen inside the scanner bore using an LCD projector (CP-SX1350, Hitachi, Tokyo, Japan). Participants' pupil diameters were monitored continuously at a sampling rate of $60 \mathrm{~Hz}$ with the EyeTrac6 Eye Tracking System (Applied Sciences Laboratories, Bedford, MA, USA). The eye camera is characterized by easily accessible focus and iris adjustments. The illuminator source is an FCR lamp (12 VDC power supply; noncoherent illumination). Eye irradiance was less than $0.5 \mathrm{~mW} / \mathrm{cm}^{3}$. Behavioral responses were recorded with a response button box (HH-1×4-CR, Current Designs, Inc., Philadelphia, PA, USA), and experimental control was performed by E-Prime 2 Professional (Psychology Software Tools, Sharpsburg, PA, USA).

\section{Dependent Variables}

Behavioral data. The dependent behavioral variables consisted of (a) the participants' errors (in \%) and (b) their RTs for correct responses (in ms) in the different experimental conditions of the visual search task.

Physiological data. The dependent physiological variables consisted of the participants' pupil diameter (in arbitrary units) and HR (in beats per minute; bpm), as well as their RR (in cycles per minute; see Supplementary Materials). For pupil diameter, a short latency signal that adapts quickly, we considered six 0.5-s intervals from 0 to $3 \mathrm{~s}$ after the search array onset. The last time interval extended the display of the search matrix by $0.5 \mathrm{~s}$ because we expected the differences 
between the experimental conditions to be somewhat sustained. Pupil diameter during $0.5 \mathrm{~s}$ before the appearance of the search matrix (final part of expectancy phase) served as baseline. Pupil diameter baseline scores were subtracted from the scores during and after stimulus presentation to obtain difference scores describing changes resulting from the presentation of the different stimuli.

HR was analyzed in 1-s intervals from 0 to $5 \mathrm{~s}$ after the search array onset, thus extending $2.5 \mathrm{~s}$ beyond the actual search matrix display. Compared with the interval used for pupil size, a longer extending interval was taken because this time was considered necessary to map at least the first two phases of the typically observed triphasic pattern (initial deceleration [reflecting an orienting response, thus constituting the most critical interval for our testing of hypotheses regarding cue-target congruency], followed by acceleration and, subsequently, by another deceleration; e.g., Lang et al., 1997) in response to pictures. HR during $1 \mathrm{~s}$ before the appearance of the search matrix (final part of expectancy phase) served as baseline. HR baseline scores were subtracted from the scores during and after stimulus presentation to obtain difference scores describing changes resulting from the presentation of the different stimuli.

\section{Results}

\section{Behavioral Data}

Error rates. Errors made up $9.7 \%$ of all responses $(S D=9.08 \%$; for an overview of the number and percentage of correct and incorrect responses per group and condition, see Table 1). Because the normal distribution assumption was violated, we calculated nonparametric statistics to test for differences in error rates between the experimental conditions.

Attention bias. We had predicted an attention bias for spiders, with spider targets being characterized by fewer errors than bird targets. To test this hypothesis, we calculated Wilcoxon tests for differences in error rates between the two targets (bird-spider). In accordance with predictions, both the test for phobic participants, $Z(19)=2.74, p<.01(M \mathrm{~s}=9.1 \%$ and $5.0 \%$ errors, for bird and spider targets, respectively; number of positive ranks $=15$, number of negative ranks $=4$, number of 
same ranks $=2)$ and that for controls, $Z(19)=2.52, p<.01(M \mathrm{~s}=12.0 \%$ and $8.2 \%$ errors, for bird and spider targets, respectively; number of positive ranks $=14$, number of negative ranks $=7$, number of same ranks $=3$ ) reached significance. Hence, as hypothesized, both groups displayed greater error rates for bird than for spider targets.

Cue-target congruency. We had predicted an influence of expectancies on the error rates for bird targets but not on the error rates for spider targets. Therefore, we first calculated four Friedman tests (see Table 1 for descriptives and rank statistics) to investigate differences between the expectancy cues for each combination of the factors Group and Target (note that, because the data violated the normal distribution, we were unable to calculate an analysis of variance [ANOVA] that would have enabled simultaneous testing of effects related to the four Friedman tests). In line with our expectations, we found an influence of the expectancy cues on error rates for bird targets in the phobic group, $\chi^{2}(2)=15.27, p<.0005$; however, the same test failed to reach significance in the control group, $\chi^{2}(2)=2.76, n s$. Subsequent Wilcoxon tests calculated for bird targets in the spider phobic group revealed a greater number of errors for spider cues than for the other cues, $Z(21)=$ 3.25 and $Z(16)=2.97$, both $p s<.005$, for bird and ambiguous cues, respectively. There was no difference between bird cues and ambiguous cues, $Z(21)=1.36, n s$. Finally, in line with our predictions, both Friedman tests performed for spider targets failed to reach significance, $\chi^{2} s(2)=$ 4.19 and 3.71, both $n s$, for phobics and controls, respectively.

Reaction times. A $2 \times 3 \times 2$ mixed-factorial design resulted from the manipulation of the between-participants factor Group (spider phobic, control) and the within-participants factors Expectancy (spider, bird, ambiguous) and Target (spider, bird). The ANOVA simultaneously tested (a) our hypothesis of an attention bias (shorter RTs for spider than for bird targets, i.e., main effect of Target, especially in the phobics, i.e., Group $\times$ Target interaction); and (b) our hypothesis that expectancy cues would have an impact on RTs for bird targets but not on RTs for spider targets (Expectancy $\times$ Target interaction). Significant effects as revealed in this ANOVA were further investigated by subordinate ANOVAs and the use of post hoc Tukey tests. An $\alpha$ level of .05 (two- 
tailed) was applied. All reported effect sizes are partial $\eta^{2}$ and are simply noted as $\eta_{p}^{2}$. Analyses were performed on correct responses only. After elimination of the error trials, $0.3 \%(S D=0.4 \%)$ of the data were outliers (RTs deviating more than $3 S D$ s from a participant's average RT on correct responses) and thus additionally excluded.

Attention bias. Consistent with our predictions, our participants displayed an attention bias for spiders (Figure 2, Table 2, main effect of Target), reflected in shorter RTs for spider than for bird targets $\left(M \mathrm{~s}=998.4\right.$ and $1276.1 \mathrm{~ms}, S D_{\text {Errors }}=26.73$ and $28.21 \mathrm{~ms}$, for spider and bird targets, respectively). Yet, somewhat unexpectedly, the attention bias was not stronger in the phobic group than in the control group (absence of significant Group $\times$ Target interaction).

Cue-target congruency. We had hypothesized that expectancy cues would have an impact on RTs for bird targets, but not on RTs for spider targets. In line with our hypotheses, the significant Expectancy $\times$ Target interaction revealed that expectancy effects were limited to bird targets: When a bird cue had been presented, RTs for bird targets were considerably shorter than when a spider or an ambiguous cue had been presented $(p s<.0005$; no difference between spider and ambiguous cues, $p>.25 ; M \mathrm{~s}=1328.0,1204.8$, and $1295.5 \mathrm{~ms}, S D_{\text {Errors }}=27.54,32.01$, and $30.33 \mathrm{~ms}$, for spider, bird, and ambiguous cues, respectively). By contrast, post hoc Tukey tests for this interaction showed no difference between the three expectancy cues for spider targets $(p s>.25$; $M \mathrm{~s}=1019.7,985.7$, and $989.8 \mathrm{~ms}, S D_{\text {Errors }}=29.00,28.09$, and $26.73 \mathrm{~ms}$, for spider, bird, and ambiguous cues, respectively). Because the same expectancy cues were used in spider and bird target trials, the missing effect for spider targets cannot be explained by an inefficient expectancy manipulation.

Of importance however, the significant Group $\times$ Expectancy $\times$ Target interaction revealed that expectancy cues had a different impact on RTs for the two targets in phobics versus controls. Therefore, we further investigated the extent to which the above-reported interaction of Expectancy and Target held for both phobics and controls, and we conducted separate ANOVAs in each group. 
Phobics displayed a significant main effect of Expectancy, $F(2,40)=7.70, p<.005, \eta_{\mathrm{p}}^{2}=.28(M \mathrm{~s}$ $=1171.5,1113.0$, and $1144.8 \mathrm{~ms}, S D_{\text {Errors }}=38.06,39.45$, and $35.69 \mathrm{~ms}$, for spider, bird, and ambiguous cues, respectively), with post hoc Tukey tests revealing significantly longer RTs for spider cues than for bird cues $(p<.005)$. The difference between bird cues and ambiguous cues was only marginally significant $(p=.09)$, with that between spider and ambiguous cues failing to reach significance $(p>.15)$. In addition, we found a significant main effect of Target, $F(1,20)=67.50, p$ $<.005, \eta_{\mathrm{p}}^{2}=.77\left(M \mathrm{~s}=1017.5\right.$ and $1268.7 \mathrm{~ms}, S D_{\text {Errors }}=42.46$ and $36.98 \mathrm{~ms}$, for spider and bird targets, respectively), corresponding to the attention bias for spiders. Unexpectedly though, there was no significant interaction of both factors, $F(2,40)=1.06, n s, \eta_{\mathrm{p}}^{2}=.05$. Thus, irrespective of type of target, bird cues were followed by faster RTs than were spider cues in this group of participants. In a similar vein, the attention bias for spider targets was independent from the earlier presented cues.

In controls, all effects achieved significance: the main effect of Expectancy, $F(2,46)=$ $16.61, p<.000005, \eta_{\mathrm{p}}^{2}=.42\left(M \mathrm{~s}=1176.1,1077.6\right.$, and $1140.6 \mathrm{~ms}, S D_{\text {Errors }}=33.78,35.10$, and $33.88 \mathrm{~ms}$, for spider, bird, and ambiguous cues, respectively); the main effect of Target, $F(1,23)=$ $65.10, p<.000001, \eta_{\mathrm{p}}^{2}=.74\left(M \mathrm{~s}=979.3\right.$ and $1283.6 \mathrm{~ms}, S D_{\text {Errors }}=33.50$ and $41.67 \mathrm{~ms}$, for spider and bird targets, respectively); and the Expectancy $\times$ Target interaction, $F(2,46)=12.75, p<$ $.00005, \eta_{p}^{2}=.36$. Post hoc Tukey tests revealed that RTs for spider targets were not influenced by the cues presented $(p \mathrm{~s}>.70$ for the three relevant comparisons; $M \mathrm{~s}=999.32,970.67$, and 967.87 $\mathrm{ms}, S D_{\text {Errors }}=38.89,48.51$, and $45.46 \mathrm{~ms}$, for spider, bird, and ambiguous cues, respectively), whereas, regarding RTs for bird targets, bird cues could be distinguished from both spider and ambiguous cues $(p s<.0005$, with no difference between spider and ambiguous cues, $p>.45 ; M \mathrm{~s}=$ 1353.0, 1184.4, and $1313.4 \mathrm{~ms}, S D_{\text {Errors }}=35.35,35.16$, and $45.46 \mathrm{~ms}$, for spider, bird, and ambiguous cues, respectively). Thus, expectancy manipulations were ineffective in modifying RTs for spider targets in the control group. 


\section{Physiological Data}

As a result of technical problems, three participants (two phobic and one control) were excluded from pupil diameter analyses, and one phobic participant was excluded from HR analyses. For pupil diameter, $6 \%$ of the time intervals analyzed constituted periods with $\geq 50 \%$ of the samples missing (mostly due to eye blinks). Consequently, these time intervals were not included in the analyses. Outliers (deviating more than $3 S D$ s from the average diameter/HR of a given participant during a particular time interval) and artifacts were eliminated (making up $4 \%$ of all pupil diameter data and approximately $1 \%$ of all HR data).

Pupil diameter. We conducted an ANOVA that relied on a 2 (Group: spider phobic, control) $\times 6$ (Time: 0-0.5 s, 0.5-1 s, 1-1.5 s, 1.5-2 s, 2-2.5 s, 2.5-3 s) $\times 3$ (Expectancy: spider, bird, ambiguous $) \times 2$ (Target: spider, bird) mixed-factorial design. The ANOVA simultaneously tested our hypotheses of (a) greater attention allocation to spider than to bird targets, especially in the phobics (main effect of Target; Group $\times$ Target interaction, including possible modulation by the factor Time); and (b) expectancy cues having an impact on pupil diameters for both bird and spider targets, with unexpected targets necessitating enhanced orienting, thus being associated with greater diameters than is the case for expected targets (Expectancy $\times$ Target interaction, including possible modulations by the factors Group and Time).

Attention bias. The ANOVA revealed no simple effect of Target, but a significant Time $\times$ Target interaction (Table 2). Separate ANOVAs for each time interval yielded a main effect of Target from 2 to $2.5 \mathrm{~s}$ after the onset of the visual search matrix only (Table 3, Figure 3 ). In conflict with our hypotheses, the increase in pupil diameter with respect to baseline was stronger for bird than for spider targets during that time $\left(M \mathrm{~s}=2.04\right.$ and $2.25, S D_{\text {Errors }}=0.19$ and 0.22 , for spider and bird targets, respectively). There was no indication of group differences regarding the attention allocation to spider versus bird targets (absence of a significant Group $\times$ Target interaction; Table $2)$. 
Cue-target congruency. The ANOVA further yielded a significant Expectancy $\times$ Target interaction (Table 2). Consistent with our hypotheses, we found an influence of expectancy cues on pupil diameter change related to bird targets (Tukey tests: bird vs. ambiguous cues, $p<.001$, other $p \mathrm{~s}>.24, M \mathrm{~s}=1.33,1.18$, and $1.48, S D_{\text {Errors }}=0.15,0.15$, and 0.17 , for spider, bird, and ambiguous cues, respectively). Although Tukey tests did not reveal a significant difference between spider and bird cues for bird targets, planned comparisons did so, $F(1,40)=5.46, p<.05$ (one-tailed). Inconsistent with predictions, however, similar effects were not observed for spider targets (Tukey tests: $p s>.97$ for all pairwise comparisons; $M \mathrm{~s}=1.24,1.30$, and $1.27, S D_{\text {Errors }}=0.14,0.14$, and 0.14, for spider, bird, and ambiguous cues, respectively). In that case, even planned comparisons of spider versus bird cues failed to reach significance, $F(1,40)=0.99, n s$.

Of note, we also found a significant Time $\times$ Expectancy $\times$ Target interaction. Subsequent ANOVAs calculated for each time interval (Table 3) showed that the differential impact of expectancy cues on pupil diameter change related to bird targets started between 1 and $1.5 \mathrm{~s}$ following the onset of the search matrix and remained stable until the end of the analysis interval (ambiguous vs. bird cues: $p$ s <.05, .01, .005, and .005, for 1-1.5 s, 1.5-2 s, 2-2.5 s, and 2.5-3 s, respectively; other pairwise comparisons for bird targets: $p s>.25$; based on Tukey tests for the Expectancy $\times$ Target interaction), whereas there were no differences between the expectancy cues for spider targets (all $p \mathrm{~s}>.69, .68, .74$, and .96, for 1-1.5 s, 1.5-2 s, 2-2.5 s, and 2.5-3 s, respectively).

Other effects. The main effect of Group in the overall ANOVA was related to the fact that control participants displayed greater increases in pupil diameter than did spider phobics $(M \mathrm{~s}=0.97$ and $1.63, S D_{\text {Errors }}=0.21$ and 0.19 , for phobics and controls, respectively). The significant Time $\times$ Group interaction arose because this group difference was absent in the first time interval $(0-0.5 \mathrm{~s}$ after search matrix appearance) and present in the remaining intervals (Table 3). The overall ANOVA further revealed a significant main effect of Expectancy (Table 2), with ambiguous cues, compared with bird cues, being associated with stronger increases in pupil diameter (Tukey tests; $p$ 
$<.05$; other pairwise comparisons: $p \mathrm{~s}>.14 ; M \mathrm{~s}=1.32,1.27$, and $1.41, S D_{\text {Errors }}=0.14,0.14$, and 0.15, for spider, bird, and ambiguous cues, respectively).

Heart rate. For our HR data, we conducted a similar ANOVA as for pupil diameter. The ANOVA simultaneously tested our hypotheses of (a) greater orienting and arousal for spider than for bird targets, especially in the phobics (main effect of Target; Group $\times$ Target interaction, including possible modulation by the factor Time); and (b) expectancy cues having an impact on attention to both bird and spider targets, with unexpected targets necessitating enhanced orienting, thus being associated with greater initial deceleration than is the case for expected targets (Expectancy $\times$ Target interaction, including possible modulations by the factors Group and Time).

Attention bias and arousal. We had predicted that attention bias (initial deceleration) and arousal differences (subsequent acceleration) would be displayed in HR, particularly so in the phobic group. The 2 (Group: spider phobic, control) $\times 5$ (Time: 0-1 s, 1-2 s, 2-3 s, 3-4 s, $4-5 \mathrm{~s}) \times 3$ (Expectancy: spider, bird, ambiguous) $\times 2$ (Target: spider, bird) ANOVA revealed a significant main effect of Target $\left(M \mathrm{~s}=-0.20\right.$ and $-0.48 \mathrm{bpm}, S D_{\text {Errors }}=0.13$ and $0.14 \mathrm{bpm}$, for spider and bird targets, respectively) and a significant Group $\times$ Target interaction (Table 2): Phobic individuals were characterized by a more elevated HR for spider than for bird targets (post hoc Tukey test, $p<$ $.01 ; M \mathrm{~s}=0.00$ and $-0.55 \mathrm{bpm}, S D_{\text {Errors }}=0.19$ and $0.21 \mathrm{bpm}$, for spider and bird targets, respectively); in contrast, controls showed comparable HRs for both bird and spider targets ( $p>$ $.99) ; M \mathrm{~s}=-0.41$ and $-0.41 \mathrm{bpm}, S D_{\text {Errors }}=0.17$ and $0.19 \mathrm{bpm}$, for spider and bird targets, respectively).

In addition, the main effect of Target was qualified by the factor Time. In order to investigate this interaction (and other interactions as revealed in the section on Cue-Target Congruency) we further performed supplemental ANOVAs for each time interval. Target and Group $\times$ Target effects appeared comparably late, namely between 2 and $5 \mathrm{~s}$ after the onset of the visual search array, demonstrating a more rapid or pronounced change from initial HR deceleration 
to HR acceleration for spider targets than for bird targets (for details, see above description of the Group $\times$ Target interaction). This suggests that arousal rather than orienting is responsible for the effect. Notably, however, the effect in the interval extending from 4 to $5 \mathrm{~s}$ was reversed for control participants; during that time, these participants displayed stronger HR acceleration for bird targets than for spider targets. Post hoc Tukey tests for the control participants' HR change in this time interval failed, however, to reach significance, $p>.12 ; M \mathrm{~s}=0.58$ and $1.02 \mathrm{bpm}, S D_{\text {Errors }}=0.28$ and $0.33 \mathrm{bpm}$, for spider and bird targets, respectively), and there was no difference between the targets in phobics at the same moment in time $\left(p>.80, M \mathrm{~s}=1.04\right.$ and $0.84 \mathrm{bpm}, S D_{\text {Errors }}=0.31$ and 0.36 bpm, for spider and bird targets, respectively).

Cue-target congruency. We had further hypothesized that the influence of the expectancy cues on our participants' HRs would be dependent on their congruency with respect to the type of target being presented. Indeed, we observed the temporal HR dynamics for the different expectancy states to vary across targets (significant Time $\times$ Expectancy $\times$ Target interaction; Table 2). Most important, there was an indication of interactive effects of Expectancy and Target in the early phase of the search task (Table 4). During that time, descriptively, spider targets were associated with stronger HR deceleration when they had been preceded by bird cues rather than by ambiguous or spider cues, whereas the reverse was true for bird targets (Figure 4). Although post hoc Tukey tests for this interaction did not reveal significant differences between the cues for either bird targets ( $p$ s $>$.16) or spider targets ( $p s>27)$, planned comparisons contrasting spider and bird cues separately for both spider and bird targets achieved (marginal) significance $(0-1 \mathrm{~s}$, bird targets: $F(1,42)=$ 3.36, $p<.05 ; 0-1 \mathrm{~s}$; spider targets: $F(1,42)=3.62, p<.05 ; 1-2 \mathrm{~s} ;$ bird targets: $F(1,42)=4.23, p<$ $.05 ; 1-2 \mathrm{~s}$; spider targets: $F(1,42)=2.46, p=.06$; all based on one-tailed testing). Thus, in line with our predictions, disconfirmation of expectancies was associated with the most enhanced initial HR deceleration. In sum, whereas there was no clear-cut indication of cue impact on the processing of spider targets in our RT and pupil dilation data, HR data did show such an influence. 
Other effects. The initial ANOVA revealed a significant Time $\times$ Expectancy interaction (Table 2). Expectancy effects were observed in the early phase after search array onset (0- to 1-s interval; Table 4), during which ambiguous cues were characterized by less HR deceleration than were spider or bird cues (Tukey tests, ambiguous vs. other cues: $p$ s $<.05$; spider vs. bird cue: $p>$ $.92 ; M \mathrm{~s}=-0.89,-0.93$, and $-0.56 \mathrm{bpm}, S D_{\text {Errors }}=0.13,0.14$, and $0.11 \mathrm{bpm}$, for spider, bird, and ambiguous cues, respectively). From 3 to $4 \mathrm{~s}$, bird cues were associated with marginally stronger acceleration than were ambiguous cues (Tukey test, $p=.05$; remaining pairwise comparisons: $p$ s > $.13 ; M \mathrm{~s}=0.43,0.81$, and $0.35 \mathrm{bpm}, S D_{\text {Errors }}=0.25,0.24$, and $0.24 \mathrm{bpm}$, for spider, bird, and ambiguous cues, respectively; similar effects were visible as trends in the preceding and subsequent intervals; Table 4).

\section{Discussion}

The current study aimed at replicating and extending the findings from our previous study (Aue, Guex, et al., 2013) that suggested the existence of expectancy influences for the detection of bird targets, but not for the detection of spider targets, possibly due to the existence of an innate fear module (Davis \& Lang, 2003; LeDoux \& Phelps, 2000; Öhman \& Mineka, 2001). Here, we additionally investigated whether and how attention bias and the influence of prior expectancies on attention to threatening versus nonthreatening targets are reflected in physiology.

\section{Attention Bias and Arousal}

We had predicted an attention bias for spiders, especially in the phobic group (cf. Bar-Haim et al., 2007; Öhman et al., 2001; Okon-Singer et al., 2013), to be reflected in shorter RTs, fewer errors, and more pronounced physiological responding (greater pupil dilation, greater initial HR deceleration) to spider targets than to bird targets. In line with our hypotheses, the participants' RTs demonstrated a clear and robust attention bias in both groups, but there was no difference between phobics and controls. Facilitated identification of spider rather than bird targets in both groups was 
also revealed in the error rates, with spider targets being characterized by less erroneous responses than bird targets.

Moreover, these effects were supplemented with target-specific changes regarding our physiological measures. However, closer inspection of the specific types of effects observed speaks to these effects as arising from arousal (cf. Flykt, 2005; Flykt et al., 2012) rather than from orienting differences between the targets. For instance, our spider phobics' HR was more elevated for spider targets than for bird targets at a comparably late moment (i.e., after the behavioral response had been given), whereas there was no difference between the targets in the early HR deceleration phase directly after the search array onset. Moreover, both groups of participants were characterized by a more enhanced (reflective of arousal; Aue, Hoeppli, \& Piguet, 2012; Flykt, 2005; Flykt et al., 2012) rather than a more reduced (reflective of orienting; Stekelenburg \& Van Boxtel, 2002) RR (see Supplementary Materials) for spider targets than for bird targets.

Effects revealed in pupil diameter were of comparably short duration and opposite to our predictions; from 2 to $2.5 \mathrm{~s}$ following the search matrix onset, pupil diameter was temporarily more increased for bird than for spider targets. Even if pupil diameter were to be considered as a measure of arousal (e.g., Bradley, Miccoli, Escrig, \& Lang, 2008) rather than orienting of attention, this effect cannot be explained because both arousal and orienting of attention have been associated with increased pupil diameters in the literature (e.g., Bradley et al., 2008; Wang \& Munoz, 2015). Yet, it must be kept in mind that the effect of Target during that time interval was qualified by the significant interaction of Expectancy and Target. Clearly, an increased diameter was observed only for those bird targets that had been preceded by incongruent (i.e., ambiguous and spider) cues. Consequently, we speculate that this effect, instead of reflecting increased arousal, indicates an elevated need for executive control (refer to Cue-Target Congruency section below for details).

Overall, our data suggest a more rapid and more arousing processing of spider than of bird targets. Importantly, participants in the control group, who were characterized by low fear or even absence of fear of spiders, displayed virtually the same behavioral and physiological responses as spider phobic individuals (except in HR, which showed interactive effects of Group and Target). 
Our findings are thus supportive of the idea of an innate fear module (Davis \& Lang, 2003; LeDoux \& Phelps, 2000; Öhman \& Mineka, 2001) that intensifies bottom-up attentional capture by phylogenetic threat (cf. Yiend, 2010; but see Lipp, 2006, for criticisms related to this issue). The observation of similar behavioral results in infants and children who have not yet acquired threatrelated fears (LoBue \& Rakison, 2013) speaks to the importance of congenital factors for these effects. Interestingly, attention biases have even been observed with abstract shapes that were associated with phylogenetic threat versus harmless animals (Batty, Cave, \& Pauli, 2005). Such a finding precludes the possibility of pop-out effects of certain classes of stimuli being responsible for the attention bias phenomenon in visual search.

\section{Cue-Target Congruency}

From our earlier research (Aue, Guex, et al., 2013), we had hypothesized that there would be asymmetric influences of the expectancy cues on vigilance to spider versus bird targets as revealed by our behavioral data, with only vigilance to bird targets being affected by the cues. Supportive evidence for this claim comes first from our phobic participants' error rates. These participants displayed greater error rates for incorrectly rather than correctly and ambiguously cued bird targets. By contrast, an influence of the expectancy cues on error rates was absent for spider targets.

Further in line with our predictions and replicating the findings from our earlier study (Aue, Guex, et al., 2013), expectancy effects revealed in the RT data were restricted to bird targets in the control group. This time, however, spider phobics revealed expectancy modulation of RTs for bird and spider targets. Somewhat counterintuitively at first glance, these participants displayed slowed rather than accelerated RTs when spider targets had been preceded by spider rather than by bird cues. (While our hypothesis predicted no RT difference for spider targets following spider cues compared with bird cues, the opposite pattern of results to that observed would have been more plausible [i.e., valid expectancy cues speeding up rather than slowing down RTs].) However, one needs to take into consideration that these participants were characterized by a slowed response for 
the identification of any stimulus that was preceded by a spider cue (main effect of Expectancy, absence of Expectancy $\times$ Target interaction). Hence, this effect may be the result of (a) phobic participants exhibiting difficulty in disengaging attention from the threatening spider cues (for evidence regarding impaired disengagement from threat, see Koster, Crombez, Verschure, \& De Houwer, 2004; Koster, Crombez, Verschure, Van Damme, \& Wiersema, 2006), or (b) these participants displaying some degree of visual avoidance (e.g., Aue, Hoeppli, et al., 2013) following the presentation of the spider cues. In both cases, focusing attention on the subsequently appearing visual search array would have been compromised.

According to Peschard and Philippot (2015), the attentional focus is determined (among other factors) by both task goals and stimulus salience, which closely relates to the notion of topdown versus bottom-up influences on attention deployment (Desimone \& Duncan, 1995). In the present experiment, the participants' goal was to detect as quickly and rapidly as possible the target, irrespective of the target's nature. Evidently, our participants pursued these task goals and were able to enhance task performance by paying attention to the expectancy cues. However, the facilitative effect provided by the cues was restricted to bird targets. Notably, Peschard and Philippot (2015) acknowledge that in some cases it might be necessary to quickly switch attention from task goals to salient sensory input, and they explicitly mention phylogenetic threat as constituting such salient input. The current experiment yields evidence for their postulate by demonstrating that stimulus salience can indeed, at least temporarily, overwrite task goals. Moreover, because the response of both spider phobics and control participants (who had been selected on the basis of particularly low spider fear) was surprisingly similar, it can be argued that stimulus saliency here has not been determined by actual or conscious fear, but by its evolutionary significance (Öhman et al., 2001; Öhman \& Mineka, 2001; Seligman, 1971; see Attention Bias and Arousal section above for details).

Common sense would have led one to predict that at least the phobic group would benefit from the presentation of the cues for their identification of spider targets because they should be in an alarm state whenever spider cues are presented. That this effect was not observed here and in our 
earlier study (Aue, Guex, et al., 2013) could be explained by the fact that human beings are endowed with specific threat detection mechanisms (Davis \& Lang, 2003; LeDoux \& Phelps, 2000; Öhman \& Mineka, 2001) that act (somewhat) independently of prior expectancies. Such independency could ultimately pay off. After all, relying erroneously on presumable safety signals can have fatal consequences in life-threatening situations. However, to date, our findings do not rule out the possibility that more significant self-relevant predictors than the cues in the current study do influence RTs.

Other researchers have shown, in contrast to the behavioral findings in the current study, that visual search may benefit from prior knowledge about the spatial location of subsequently appearing targets (e.g., Mohanty, Egner, Monti, \& Mesulam, 2009; Mohanty, Gitelman, Small, \& Mesulam, 2008). What is more, anticipation of the type of deviating emotional facial expression (including threatening displays) in a search array has also been reported to accelerate RTs (Hahn \& Gronlund, 2007; M. A. Williams, Moss, Bradshaw, \& Mattingley, 2005). However, these studies differ from our own in important ways. Apart from the fact that these studies included other stimulus material (i.e., facial expressions), the participants were not preinformed about the likelihood of any stimulus being the (deviant) target, whereas we varied these likelihoods on a trialto-trial basis via the presentation of the expectancy cues. Further differences consist in these authors using (a) only a single target (Hahn \& Gronlund, 2007), or (b) the same facial expressions as distractors in some trials and targets in other experimental trials (thus including only two stimulus categories; e.g., neutral among happy expressions and happy among neutral expressions; M. A. Williams et al., 2005). Any of these factors may have rendered these tasks less difficult than our own.

One study (Mohanty et al., 2009), however, used a cueing procedure that was highly similar to ours for the detection of tilted targets (i.e., faces) in a search array. In contrast to our own results, in this study, RTs to angry facial expressions (indexing phylogenetic threat) were demonstrated to be influenced by prior knowledge about the location and type of the to-be-detected stimulus. Such 
anticipation-based visual search has been suggested to rely on activity in a fronto-parietal attention network (comprising the frontal eye fields, the posterior parietal cortex, and the posterior cingulate cortex; Mohanty \& Sussman, 2013) that exerts causal influences on visual cortex activity. Hence, Mohanty et al.'s (2009) results are in line with the so-called predictive coding theory that states that human beings establish mental templates about future happenings to which incoming sensory information is compared (e.g., Summerfield et al., 2006; Zelano, Mohanty, \& Gottfried, 2011). Of note, the search display in the Mohanty et al. (2009) study consisted of only four simultaneously presented facial expressions, and valid spatial cueing required the participants to make a decision between only two elements in the search array. Again, this may have rendered the task easier than our own.

Along these lines, the importance of the number of distractors in visual search arrays has been demonstrated by several works. Öhman et al. (2001) reported the detection of snake targets to be uninfluenced by the number of distractors (three vs. eight), whereas this was not the case for the detection of fear-irrelevant (e.g., flowers) targets. The authors interpreted these results as evidence for preattentive, parallel processing of phylogenetic threat, whereas search for fear-irrelevant targets relied on postattentive, serial processing. Comparably, Lipp, Derakshan, Waters, and Logies (2004, Experiment 1) reported their participants to display an increase in search advantage for phylogenetic threat over harmless stimuli when the number of elements in the search matrix was increased from four to nine. Moreover, this advantage for threat over nonthreat was revealed for different types of background distractors (i.e., for phylogenetic threat distractors as well as for harmless distractors). Something that should be taken into account, however, is that in Lipp et al.'s (2004, Experiment 1) study, the identification of both threat and fear-irrelevant targets in the matrix containing nine (rather than four) elements was slowed. Thus, when perceptual resources are depleted, even the processing of phylogenetic threat stimuli may, at least partly, rely on serial information processing. 
In our own experiment, we used a search array with nine elements, which corresponds to the high perceptual load conditions in these earlier studies. According to the ideas raised by Öhman et al. (2001), RT differences between threat and nonthreat should therefore be magnified. Our data actually conform to these ideas. Specifically, parallel processing of the threatening spider targets may have prevented the expectancy cues from making an impact. Nonthreat, instead, which is supposed to be processed serially, should then indeed be more prone to top-down influences such as prior expectancies. Consequently, from the RTs, one might be tempted to conclude that, instead of gating visual search for phylogenetic threat, the expectancy cues' influence is restricted to later processing stages. Yet, such an interpretation is challenged by our HR data that yield evidence for an early consideration of cue-target congruency even in the case of phylogenetic threat (discussed in detail below). Future research should vary matrix sizes in order to further investigate this issue.

Apart from behavioral preparation, we examined the degree to which our anticipated effects in behavior would be complemented by physiological effects. Specifically, we had hypothesized that expectancy confirmation and violation, even if not influencing behavioral responding, would be registered by the organism. Given the greater need of orienting in case of incongruent rather than congruent cueing, we had predicted opposite influences of the expectancy cues on the two targets. Inconsistent with these predictions, expectancy influences on pupil diameter were restricted to bird targets (smallest diameter for bird cues), but, again, no such influence was found for the experimental trials with spider targets. Hence, these pupil data reveal effects that closely resemble the behavioral effects reported above.

Of importance, though, is that the asymmetric effects in behavior and pupil diameter were not mirrored in our HR data: These data did show cue-target congruency for both types of targets and both groups of participants. Basically, in accordance with our hypotheses, HR indeed revealed a greater orienting response (i.e., initial HR deceleration; cf. Bradley \& Lang, 2007; Stekelenburg \& Van Boxtel, 2002) in the case that expectancies had been disconfirmed rather than confirmed. It remains to be clarified why the cue-target congruency effect as revealed in our participants' HR 
data is not also reflected in their behavioral responses, pupil diameter, and RR. One possible interpretation would be that HR effects in the current study, contrary to our initial considerations, were actually unrelated to reorienting of attention.

However, an alternative interpretation of the data, to us, appears to be more appropriate: First, one needs to take into account that RT constitutes a single-moment snapshot measure, whereas our HR data were assessed continuously and therefore may have revealed temporal effects that, when integrated, can be hidden in RT data. Second, pupil diameter has been related not to only a single network, but to at least three different attention networks, with the activations of these networks being temporally distinct (Geva, Zivan, Warsha, \& Olchik, 2013). According to these conceptions, orienting effects in pupil diameter precede effects associated with executive control. Comparison of our own pupil diameter data with the timelines provided by Geva et al. (2013) suggests that the expectancy variations during the detection of bird targets constitute an index of differential degrees of executive control rather than orienting. A fear module may render executive control for the processing of phylogenetic threat largely dispensable, which could explain the absence of expectancy influences on pupil diameter for spider targets.

The interpretation of HR effects representing orienting characteristics and pupil dilation representing executive control characteristics is further supported by the fact that the critical interaction between Expectancy and Target in the present study arises earlier in HR than in pupil diameter. Finally, RR, as a long latency signal, may have lacked the level of sensitivity that is necessary to capture fine-grained temporal variations in attention.

In sum, our behavioral and pupil diameter data are in line with the postulate of specific attentional systems for phylogenetically salient stimuli such as threatening animals. These systems may be intimately linked with amygdala activity and ensure automatic information processing (Cisler \& Koster, 2010) that overwrites current task goals. In contrast to the permeability of detection systems for neutral stimuli, the penetration of these threat-specific systems by prior (experimentally induced) expectancies may be more restricted. While our HR data suggest that 
early attention to threat might still be somewhat influenced by prior expectancies, this influence may often be too feeble to be translated into behavior; it is possible that expectancy influences during the detection of spider targets are only weak and transient, and then are quickly overwritten by the strong effects evoked by the spider targets. It is still imaginable that later, more strategic, attention biases such as visual avoidance (which we did not measure in the current experiment) are linked with prior expectancies. A study by Rohner (2004), for instance, suggests that prior information about the location of angry faces is associated with more efficient visual avoidance in anxious participants. Our own observation that visual avoidance (but not early visual attention) is associated with encounter expectancies for spiders (Aue, Hoeppli, et al., 2013) is consistent with such a conception. Further in agreement with these reflections, Everaert et al. (2012) described the interplay between congruent biases in attention and memory in depression as being limited to later information processing stages.

\section{Limitations}

Some limitations of our study need to be mentioned. We informed our participants that, in $90 \%$ of the cases, spider and bird expectancy cues would correctly prime the target in the search array. Yet, to ascertain a sufficiently high number of valid samples in incongruent priming trials, we had correct priming in only $70 \%$ of these cases. Providing our participants with a reference point of $90 \%$ instead of $70 \%$ aimed at increasing expectancy influences on visual search. An unwanted side effect, however, may have been that our participants felt wrongly informed, which may have resulted in lowered trust in the expectancy cues. Experienced discrepancy between explicit (i.e., instructed) and implicit expectancies may then have led participants to no longer follow the cues rather than augmenting their impact.

Yet, three important considerations speak against a complete mistrust with respect to the expectancy cues. First, there is evidence in the literature that instructions about proportions can be sufficient to produce corresponding behavioral effects (Entel, Tzelgov, \& Bereby-Meyer, 2014, Experiment 1), even if the information that is given does not match the real proportions. Second, 
even with the $70 \%$ chance, our participants experienced spider and bird cues to correctly prime the targets in the majority of cases. Consequently, implicitly, they should have learned that these cues had at least some predictive power with respect to the target; when seeing the spider $90 \%$ expectancy cue, they should still have felt that there was a higher likelihood of a spider rather a bird being the target. Third, that our expectancy cues may have been distrusted overall is refuted by our data regarding bird targets. The fact that we found robust expectancy effects for the bird targets across various behavioral and physiological parameters demonstrates that our participants recognized the cues and trusted them at least to some degree. Because similar expectancy cues had been used for bird and spider targets, differences between the targets cannot be explained by our participants not having considered the expectancy cues. These considerations notwithstanding, we cannot rule out that an increase in predictability (i.e., salience) of the expectancy cues may result in more robust expectancy influences on the identification of spider targets.

In addition, we cannot dismiss the possibility that we might have found more convincing evidence for expectancy influences on attention to spider targets with a larger sample size. However, inspection of the corresponding effect sizes revealed these to be negligible, and adding more participants should not have much of an impact. Hence, the vast absence of significant results regarding the importance of the expectancy cues for the processing of spider targets does not seem to be a question of statistical power. Moreover, results in the current study largely replicate our earlier behavioral findings (Aue, Guex, et al., 2013), which further emphasizes the robustness of the effects. In conclusion, we do not renounce the possibility that expectancies influence the detection of spider targets, but the detection mechanism for phylogenetic threat stimuli clearly does not appear to be as permeable to expectancies as attentive systems that are responsible for the detection of harmless stimuli.

\section{Summary and Future Directions}

Behavioral and physiological data in the current study revealed the existence of an attention bias in phobics and controls. More important, we found no simple facilitative effect of the expectancy cues 
on the identification of spider targets. That our expectancy manipulation was successful, though, was revealed in the RTs for bird targets (and also in the phobic participants' error rates), which clearly showed facilitation and complication effects by the verbal expectancy cues that had been presented earlier. We have pointed to the possibility of the existence of attentional systems specific to the detection of phylogenetically salient stimuli such as threatening animals. In contrast to detection systems for neutral stimuli, the penetration of these threat-specific systems by prior (experimentally induced) expectancies may be more restricted. In fact, our data revealed a greater and more straightforward influence of expectancies on attention to the harmless birds.

It is possible that more time-sensitive measures (rather than single-moment snapshot data such as RTs) reveal greater influences of expectancies on attention to threatening stimuli. Our HR, but not our pupil diameter, findings are consistent with such an idea. Adding electroencephalographic recordings to the list of dependent variables may further increase our knowledge on the temporal dynamics of expectancy influences on attention allocation. Future research should also test whether the effects observed in our RTs originate in attentional or motor processes. Despite the fact that the visual search task is considered to measure attentional capture, we cannot rule out the possibility that part of the differences in RTs observed here result from facilitated or complicated motor responses. The inclusion of electromyographic measures and neuroimaging in subsequent studies may help to further elucidate this point.

While there is some evidence regarding the influence of expectancy on attentional processes in the current research, the reverse link deserves consideration as well. It is imaginable that different expectations originate in differences in attention (e.g., vigilance vs. avoidance). Moreover, although in our previous research (Aue, Guex, et al., 2013) we had initially hypothesized that memory processes would mediate the effects of expectancies on attention deployment (see Olivers, Peters, Houtkamp, \& Roelfsema, 2011; Soto, Hodsoll, Rotshtein, \& Humphreys, 2008, for discussions of and conditions for memory-based attention), we did not explicitly measure working memory content in this previous study or in the current study. The simultaneous investigation of working 
memory content could therefore help to further elucidate the effects obtained here. Generally, the inclusion of other processing biases (e.g., in memory and interpretation) in the study of expectancyattention associations is indispensable (see Aue \& Okon-Singer, 2015, for details). Recent research is supportive of the idea that memory and interpretation peculiarities may play fundamental roles in expectancy formation and attention deployment, in health as well as in psychopathology (e.g., Blaut, Paulewicz, Szastok, Prochwicz, \& Koster, 2013; Hutchinson \& Turk-Browne, 2012; LeMoult \& Joormann, 2012).

Finally, future research needs to test whether the effects observed for spider targets in the current study are characteristic of phylogenetically salient stimuli or whether they translate to other, more recent threat signals (e.g., guns and knives), to all kinds of negative (including, for instance, disgusting or saddening) stimuli, or even to all kinds of emotional (including positive) stimuli. In fact, contemporary publications discuss the possibility that positive attention biases might be closely associated with positive expectancy biases (e.g., overoptimism or wishful thinking; Aue, Nusbaum, \& Cacioppo, 2012; Krizan \& Windschitl, 2007). Better knowledge of the interplay between different types of positive cognitive biases, and their similarities and differences with respect to threat-related and other negative cognitive biases, may therefore be most stimulating. 


\section{References}

American Psychiatric Association. (2000). Diagnostic and statistical manual of mental disorders (4th ed., text rev.). Washington, DC: Author.

Amir, N., Foa, E. B., \& Coles, M. E. (1998). Automatic activation and strategic avoidance of threatrelevant information in social phobia. Journal of Abnormal Psychology, 107, 285-290.

Amrhein, C., Pauli, P., Dengler, W., \& Wiedemann, G. (2005). Covariation bias and its physiological correlates in panic disorder patients. Journal of Anxiety Disorders, 19, 177-191.

Aue, T., Guex, R., Chauvigné, L. A. S., \& Okon-Singer, H. (2013). Varying expectancies and the attention bias in phobic and non-phobic individuals. Frontiers in Human Neuroscience, 7 , 418.

Aue, T., \& Hoeppli, M. E. (2012). Evidence for an encounter expectancy bias in fear of spiders. Cognition and Emotion, 26, 727-736.

Aue, T., Hoeppli, M. E., \& Piguet, C. (2012). The sensitivity of physiological measures to phobic and non-phobic fear intensity. Journal of Psychophysiology, 26, 154-167.

Aue, T., Hoeppli, M. E., Piguet, C., Hofstetter, C., Rieger, S. W., \& Vuilleumier, P. (2015). Brain systems underlying expectancy bias in spider phobia. Cognitive, Affective and Behavioral Neuroscience, $15,335-348$.

Aue T., Hoeppli, M. E., Piguet, C., Sterpenich, V., \& Vuilleumier, P. (2013). Visual avoidance in phobia: Particularities in neural activity, autonomic responding, and cognitive risk evaluations. Frontiers in Human Neuroscience, 7, 194.

Aue, T., Nusbaum, H. C., \& Cacioppo, J. T. (2012). Neural correlates of wishful thinking. Social Cognitive and Affective Neuroscience, 7, 991-1000.

Aue, T., \& Okon-Singer, H. (2015). Expectancy biases in fear and anxiety and their link to biases in attention. Clinical Psychology Review, 42, 83-95.

Bar-Haim, Y, Lamy, D., Pergamin, L., Bakermans-Kranenburg, M. J., \& van IJzendorn, M. H. (2007). Threat-related attentional bias in anxious and nonanxious individuals: A meta-analytic 
study. Psychological Bulletin, 133, 1-24.

Batty, M. J., Cave, K. R., \& Pauli, P. (2005). Abstract stimuli associated with threat through conditioning cannot be detected preattentively. Emotion, 5, 418-430.

Blaut, A., Paulewicz, B., Szastok, M., Prochwicz, K., \& Koster, E. (2013). Are attentional bias and memory bias for negative words causally related? Journal of Behavior Therapy and Experimental Psychiatry, 44, 293-299.

Bradley, M. M., \& Lang, P. (2007). Emotion and motivation. In J. T. Cacioppo, L. G. Tassinary, \& G. G. Berntson (Eds.), Handbook of psychophysiology (3 ${ }^{\text {rd }}$ ed., pp 581-607). New York, NY: Cambridge University Press.

Bradley, M. M., Miccoli, L., Escrig, M. A., \& Lang, P. J. (2008). The pupil as a measure of emotional arousal and autonomic activation. Psychophysiology, 45, 602-607.

Butler, G., \& Mathews, A. (1983). Cognitive processes in anxiety. Advances in Behaviour Research and Therapy, 5, 51-62.

Cisler, J. M., \& Koster, E. H. W. (2010). Mechanisms of attentional biases towards threat in anxiety disorders: An integrative review. Clinical Psychology Review, 30, 203-216.

Dan-Glauser, E. S., \& Scherer, K. R. (2011). The Geneva Affective PicturE Database (GAPED): A new 730 picture database focusing on valence and normative significance. Behavior Research Methods, 43, 468-477.

Davis, M., \& Lang, P. J. (2003). Emotion. In M. Gallagher \& R. J. Nelson (Eds.), Handbook of psychology: Volume 3. Biological psychology (pp. 405-439). New York, NY: Wiley.

de Jong, P. J., \& Muris, P. (2002). Spider phobia: Interaction of disgust and perceived likelihood of involuntary physical contact. Anxiety Disorders, 16, 51-65.

Desimone, R., \& Duncan, J. (1995). Neural mechanisms of selective visual attention. Annual Review of Neuroscience, 18, 193-222.

Duncan, J., \& Humphreys, G. (1989). Visual search and stimulus similarity. Psychological Review, $96,433-458$. 
Entel, O., Tzelgov, J., \& Bereby-Meyer, Y. (2014). Proportion congruency effects: Instructions may be enough. Frontiers in Psychology, 5, 1108.

Everaert, J., Koster, E. H. W., \& Derakshan, N. (2012). The combined cognitive bias hypothesis in depression. Clinical Psychology Review, 32, 413-424.

Flykt, A. (2005). Visual search with biological threat stimuli: Accuracy, reaction times, and heart rate changes. Emotion, 5, 349-353.

Flykt, A., Lindeberg, S., \& Derakshan, N. (2012). Fear makes you stronger: Responding to feared animal targets in visual search. Attention, Perception, and Psychophysics, 74, 1437-1445.

Foa, E. B., Franklin, M. E., Perry, K. J., \& Herbert, J. D. (1996). Cognitive biases in generalized social phobia. Journal of Abnormal Psychology, 105, 433-439.

Foa, E. B., \& Kozak, M. J. (1986). Emotional processing of fear: Exposure to corrective information. Psychological Bulletin, 99, 20-35.

Fox, E., Russo, R., Bowles, R., \& Dutton, K. (2001). Do threatening stimuli draw or hold visual attention in subclinical anxiety? Journal of Experimental Psychology: General, 130, 681-700.

Fox, E., Russo, R., \& Dutton, K. (2002). Attentional bias for threat: Evidence for delayed disengagement from emotional faces. Cognition and Emotion, 16, 355-379.

Gauthier, J. B., \& Bouchard, S. (1993). Adaptation canadienne-française de la version révisée du State-Trait Anxiety Inventory de Spielberger. Canadian Journal of Behavioral Sciences, 25, $559-578$.

Geva, R., Zivan, M., Warsha, A., \& Olchik, D. (2013). Alerting, orienting or executive attention networks: Differential patterns of pupil dilations. Frontiers in Behavioral Neuroscience, 7 , 145.

Hahn, S., \& Gronlund, S. D. (2007). Top-down guidance in visual search for facial expressions. Psychonomic Bulletin and Review, 14, 159-165.

Hermans, D., Vansteenwegen, D., \& Eelen, P. (1999). Eye movement registration as a continuous index of attention deployment: Data from a group of spider anxious students. Cognition and Emotion, 13, 419-434. 
Hirsch, C. R., Clark, D. M., \& Mathews, A. (2006). Imagery and interpretations in social phobia: Support for the combined cognitive biases hypothesis. Behavior Therapy, 37, 223-236.

Hutchinson, J. B., \& Turk-Browne, N. B. (2012). Memory-guided attention: Control from multiple memory systems. Trends in Cognitive Sciences, 16, 576-579.

Ingram, R. E. (1984). Toward an information-processing analysis of depression. Cognitive Therapy and Research, 8, 443-477.

Koster, E. H. W., Crombez, G., Verschuere, B., \& De Houwer, J. (2004). Selective attention to threat in the dot probe paradigm: Differentiating vigilance and difficulty to disengage. Behaviour Research and Therapy, 42, 1183-1192.

Koster, E. H. W., Crombez, G., Verschuere, B., Van Damme, S., \& Wiersema, J. R. (2006). Components of attentional bias to threat in high trait anxiety: Facilitated engagement, impaired disengagement, and attentional avoidance. Behaviour Research and Therapy, 44, $1757-1771$.

Krizan, Z., \& Windschitl, P. D. (2007). The influence of outcome desirability on optimism. Psychological Bulletin, 133, 95-121.

Lang, P. J., Bradley, M. M., \& Cuthbert, B. N. (1997). Motivated attention: Affect, activation, and action. In P. J. Lang, R. F. Simons, \& M. T. Balaban (Eds.), Attention and orienting: Sensory and motivational processes (pp. 97-135). Mahwah, NJ: Lawrence Erlbaum.

LeDoux, J. E., \& Phelps, E. A. (2000). Emotional networks in the brain. In M. Lewis \& J. M. Haviland-Jones (Eds.), Handbook of emotions (pp. 157-172). New York: Guilford Press.

LeMoult, J., \& Joormann, J. (2012). Attention and memory biases in social anxiety disorder: The role of comorbid depression. Cognitive Therapy and Research, 36, 47-57.

Lipp, O. V. (2006). Of snakes and flowers: Does preferential detection of pictures of fear-relevant animals in visual search reflect fear-relevance? Emotion, 6, 296-308.

Lipp, O. V., Derakshan, N., Waters, A. M., \& Logies, S. (2004). Snakes and cats in the flower bed: Fast detection is not specific to pictures of fear-relevant animals. Emotion, 4, 233-250. 
LoBue, V., \& Rakison, D. H. (2013). What we fear most: A developmental advantage for fearrelevant stimuli. Developmental Review, 33, 285-303.

Lynn, R. (1966). Attention, arousal, and the orientation reaction. Oxford: Pergamon.

Mathews, A., Mackintosh, B., \& Fulcher, E. P. (1997). Cognitive biases in anxiety and attention to threat. Trends in Cognitive Sciences, 1, 340-345.

McManus, F., Clark, D. M., \& Hackmann, A. (2000). Specificity of cognitive biases in social phobia and their role in recovery. Behavioural and Cognitive Psychotherapy, 28, 201-209.

Mendes, W. B., Blascovich, J., Hunter, S. B., Lickel, B., \& Jost, J. T. (2007). Threatened by the unexpected: Physiological responses during social interactions with expectancy-violating partners. Journal of Personality and Social Psychology, 92, 698-716.

Mogg, K., \& Bradley, B. P. (1998). A cognitive-motivational analysis of anxiety. Behaviour Research and Therapy, 36, 809-848.

Mogg, K., Bradley, B. P., DeBono, J., \& Painter, M. (1997). Time course of attentional bias for threat information in non-clinical anxiety. Behaviour Research and Therapy, 35, 297-303.

Mohanty, A., Egner, T., Monti, J. M., \& Mesulam, M. M. (2009). Search for a threatening target triggers limbic guidance of spatial attention. Journal of Neuroscience, 29, 10563-10572.

Mohanty, A., Gitelman, D. R., Small, D. M., \& Mesulam, M. M. (2008). The spatial attention network interacts with limbic and monoaminergic systems to modulate motivation-induced attention shifts. Cerebral Cortex, 18, 2604-2613.

Mohanty, A., \& Sussman, T. J. (2013). Top-down modulation of attention by emotion. Frontiers in Human Neuroscience, 7, 102.

Mühlberger, A., Wiedemann, G., Herrmann, M. J., \& Pauli, P. (2006). Phylo- and ontogenetic fears and the expectation of danger: Differences between spider- and flight-phobic subjects in cognitive and physiological responses to disorder-specific stimuli. Journal of Abnormal Psychology, 115, 580-589. 
Muris, P., Huijding, J., Mayer, B., den Breejen, E., \& Makkelie, M. (2007). Spider fear and covariation bias in children and adolescents. Behaviour Research and Therapy, 45, 26042615.

Öhman, A., Flykt, A., \& Esteves, F. (2001). Emotion drives attention: Detecting the snake in the grass. Journal of Experimental Psychology: General, 130, 466-478.

Öhman, A., \&, Mineka, S. (2001). Fears, phobias, and preparedness: Toward an evolved module of fear and fear learning, Psychological Review, 108, 483-522.

Okon-Singer, H., Lichtenstein-Vidne, L., \& Cohen, N. (2013). Dynamic modulation of emotional processing. Biological Psychology, 92, 480-491.

Olivers, C. N. L., Peters, J. C., Houtkamp, R., \& Roelfsema, P. R. (2011). Different states in visual working memory: Then it guides attention and when it does not. Trends in Cognitive Sciences, 15, 327-334.

Peschard, V., \& Philippot, P. (2015). Social anxiety and information processing biases: an integrated theoretical perspective. Cognition and Emotion.

Rohner, J.-C. (2004). Memory-based attentional biases: Anxiety is linked to threat avoidance. Cognition and Emotion, 18, 1027-1054.

Sebastiani, L., D’Alessandro, L., \& Gemignani, A. (2014). Does fear expectancy prime fear? An autonomic study in spider phobics. International Journal of Psychophysiology, 91, 178-185.

Seligman, M. E. P. (1971). Phobias and preparedness. Behavior Therapy, 2, 307-320.

Soares, S. C., Esteves, F., Lundqvist, D., \& Öhman, A. (2009). Some animal specific fears are more specific than others: Evidence from attention and emotion measures. Behavioural Research and Therapy, 47, 1032-1042.

Sokolov, E. N. (1963). Higher nervous functions: The orienting reflex. Annual Review of Physiology, 25, 545-580.

Soto, D., Hodsoll, J., Rotshtein, P., \& Humphreys, G. W. (2008). Automatic guidance of attention from working memory. Trends in Cognitive Sciences, 12, 342-348. 
Spielberger, C. D. (1983). Manual for the State-Trait Anxiety Inventory (Form Y). Palo Alto, CA: Consulting Psychologist Press.

Steiner, G. Z., \& Barry, R. J. (2011). Pupillary responses and event-related potentials as indices of the orienting reflex. Psychophysiology, 48, 1648-1655.

Stekelenburg, J. J., \& Van Boxtel, A. (2002). Pericranial muscular, respiratory, and heart rate components of the orienting response. Psychophysiology, 39, 707-722.

Summerfield, C., Egner, T., Greene, M., Koechlin, E., Mangels, J., \& Hirsch, J. (2006). Predictive codes for forthcoming perception in the frontal cortex. Science, 314, 1311-1314.

Szymanski, J., \& O'Donohue, W. T. (1995). Fear of Spiders Questionnaire. Journal of Behavior Therapy and Experimental Psychiatry, 26, 31-34.

Taylor, S., \& Rachman, S. (1994). Stimulus estimation and the overprediction of fear. British Journal of Clinical Psychology, 33, 173-181.

Wang, C.-A., \& Munoz, D. P. (2015). A circuit for pupil orienting responses: Implications for cognitive modulation of pupil size. Current Opinion in Neurobiology, 33, 134-140.

Williams, J. M. G., Watts, F. N., MacLeod, C., \& Mathews, A. (1997). Cognitive psychology and emotional disorders. New York, NY: Wiley.

Williams, M. A., Moss, S. A., Bradshaw, J. L., \& Mattingley, J. B. (2005). Look at me, I'm smiling: Visual search for threatening and nonthreatening facial expressions. Visual Cognition, 12, 2950.

Wolfe, J. M. (2010). Visual search. Current Biology, 20, R346-R349.

Wolfe, J. M., Butcher, S. J., Lee, C., \& Hyle, M. (2003). Changing your mind: On the contributions of the top-down and bottom-up guidance in visual search for feature singletons. Journal of Experimental Psychology: Human Perception and Performance, 29, 483-502.

World Health Organization. (1992). International statistical classification of diseases and related health problems (10th rev.). Geneva, Switzerland: Author.

World Medical Association. (1999). Proposed revision of the Declaration of Helsinki. British Medical Journal, 147, 18-22. 
Yiend, J. (2010). The effects of emotion on attention: A review of attentional processing of emotional information. Cognition and Emotion, 24, 3-47.

Yiend, J., \& Mathews, A. (2001). Anxiety and attention to threatening pictures. Quarterly Journal of Experimental Psychology, 54, 665-681.

Zelano, C., Mohanty, A., \& Gottfried, J. A. (2011). Olfactory predictive codes and stimulus templates in piriform cortex. Neuron, 72, 178-187. 
Acknowledgements

This research was supported by grant PZ001P1_121590 of the Swiss National Science Foundation to Tatjana Aue. 


\section{Footnotes}

${ }^{1}$ More concretely, we had hypothesized that high expectancies regarding the appearance of threatening (i.e., spiders) versus nonthreatening (i.e., birds) animals would effectuate a top-down influence on visual search for threat by activating adequate working memory content (for evidence of memory-guided attention, see Duncan \& Humphreys, 1989; Hutchinson \& Turk-Browne, 2012; Wolfe, 2010; Wolfe, Butcher, Lee, \& Hyle, 2003). Memory could thus act as a mediator in the expectancy-attention association. More proximal influences between processes related to expectancies and attention are also imaginable. For instance, expectancies might exert a top-down influence on the engagement of attention simply because highly fearful individuals who expect to encounter spiders with a comparably high likelihood are more strongly motivated to overcome obstacles; this increased motivation might then be expressed in stronger vigilance.

${ }^{2}$ Along these lines, other research indeed suggests that confirmation versus disconfirmation of expectancies may impact physiological responding (e.g., Mendes, Blascovich, Hunter, Lickel, \& Jost, 2007; Sebastiani, D’Alessandro, \& Gemignani, 2014). 
Figure Captions

Figure 1. Example of experimental trial. Spider $90 \%$, bird $90 \%$, and spider-bird $50 \%$ refer to the expectancy of the target to be a spider or a bird. Jitters have been introduced to prevent habituation.

Figure 2. Reaction times as a function of Group, Expectancy, and Target. Spider cue, bird cue, and ambiguous cue refer to the spider $90 \%$, bird 90\%, and spider-bird [bird-spider] $50 \%$ cues, respectively. Error bars depict standard errors.

Figure 3. Pupil diameter change as a function of Time, Expectancy, and Target. Spider cue, bird cue, and ambiguous cue refer to the spider 90\%, bird 90\%, and spider-bird [bird-spider] 50\% cues, respectively. Error bars depict standard errors.

Figure 4. Heart rate change as a function of Time, Expectancy, and Target. Spider cue, bird cue, and ambiguous cue refer to the spider $90 \%$, bird 90\%, and spider-bird [bird-spider] $50 \%$ cues, respectively. Error bars depict standard errors. 


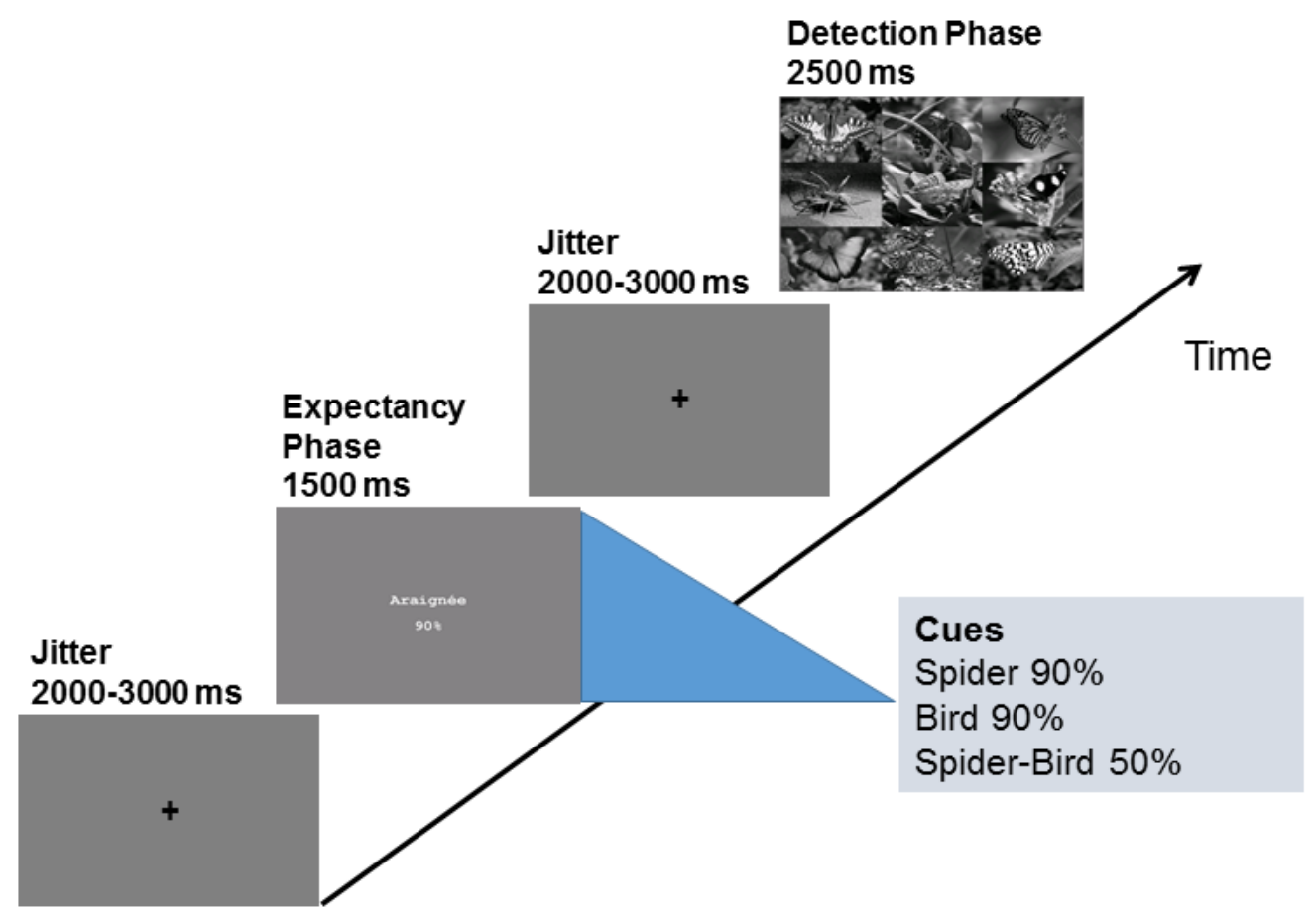




\section{Reaction Times (in ms)}

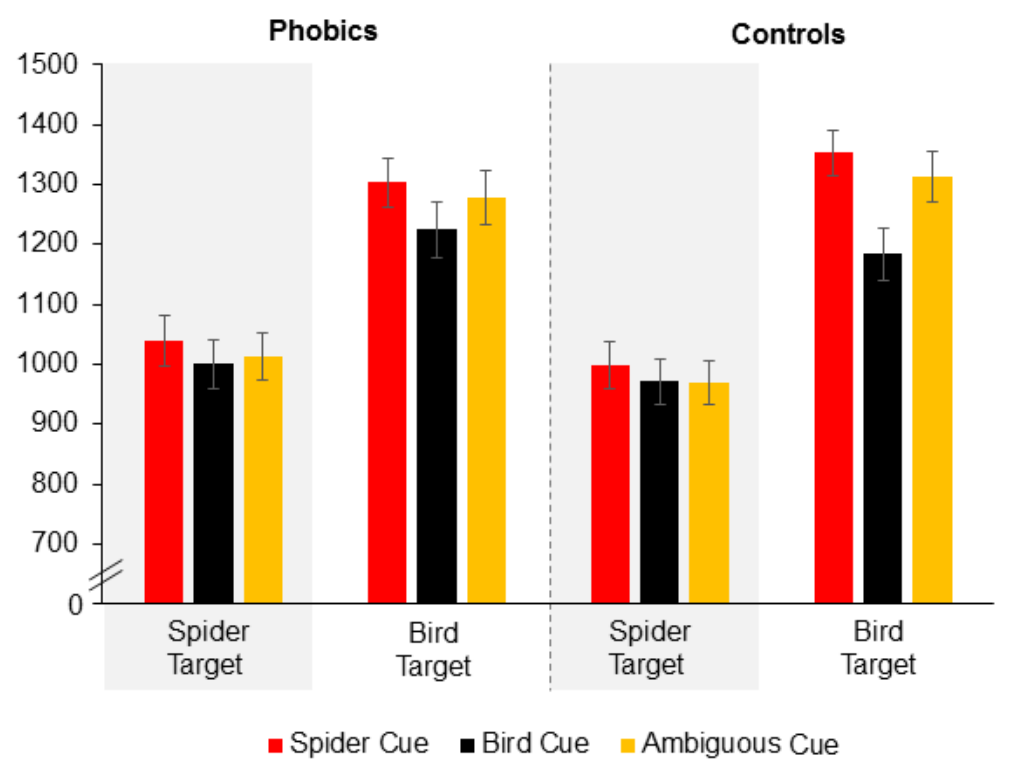


Pupil Size Change (in arbitrary units)

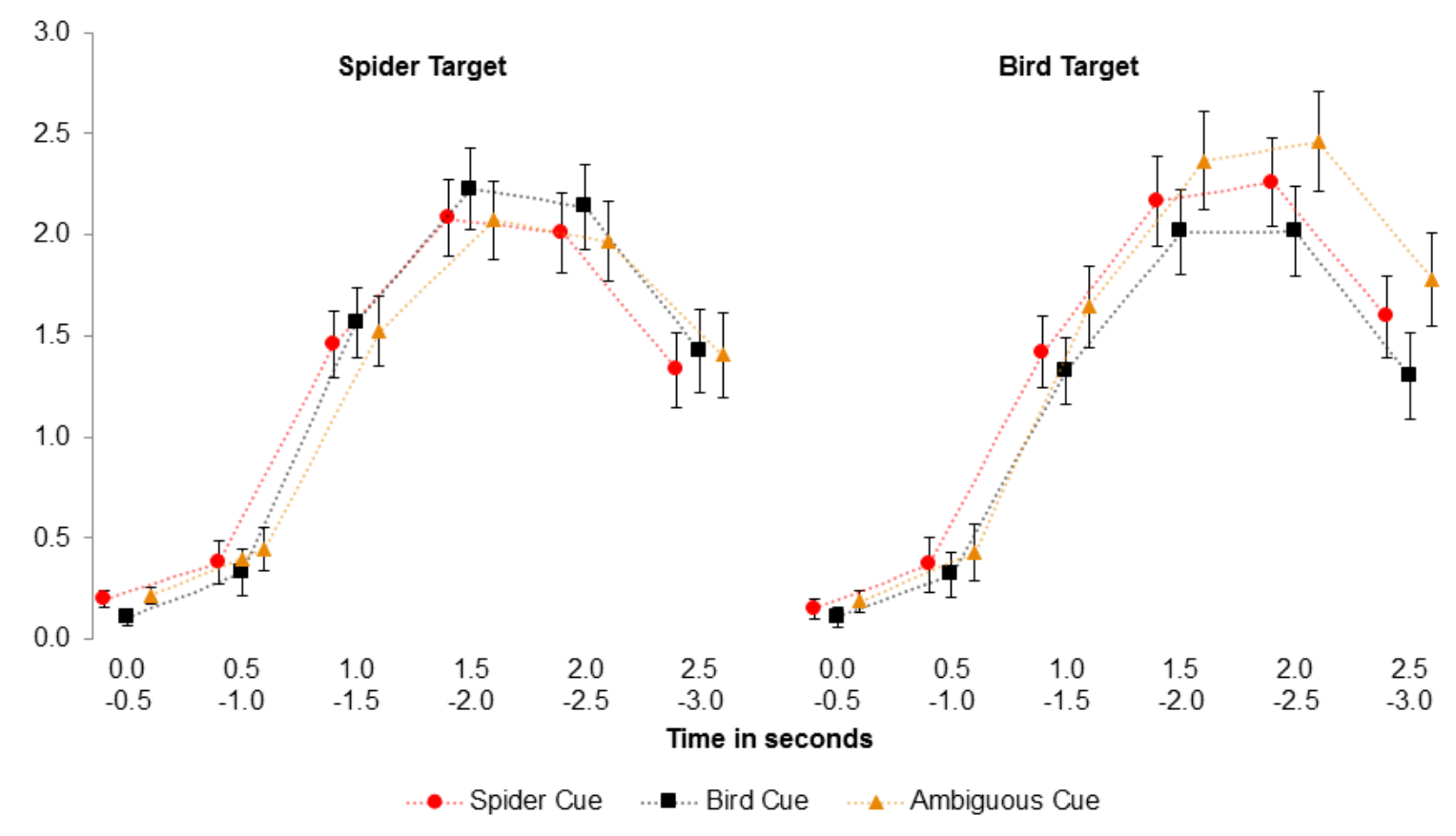


Heart Rate Change (in bpm)

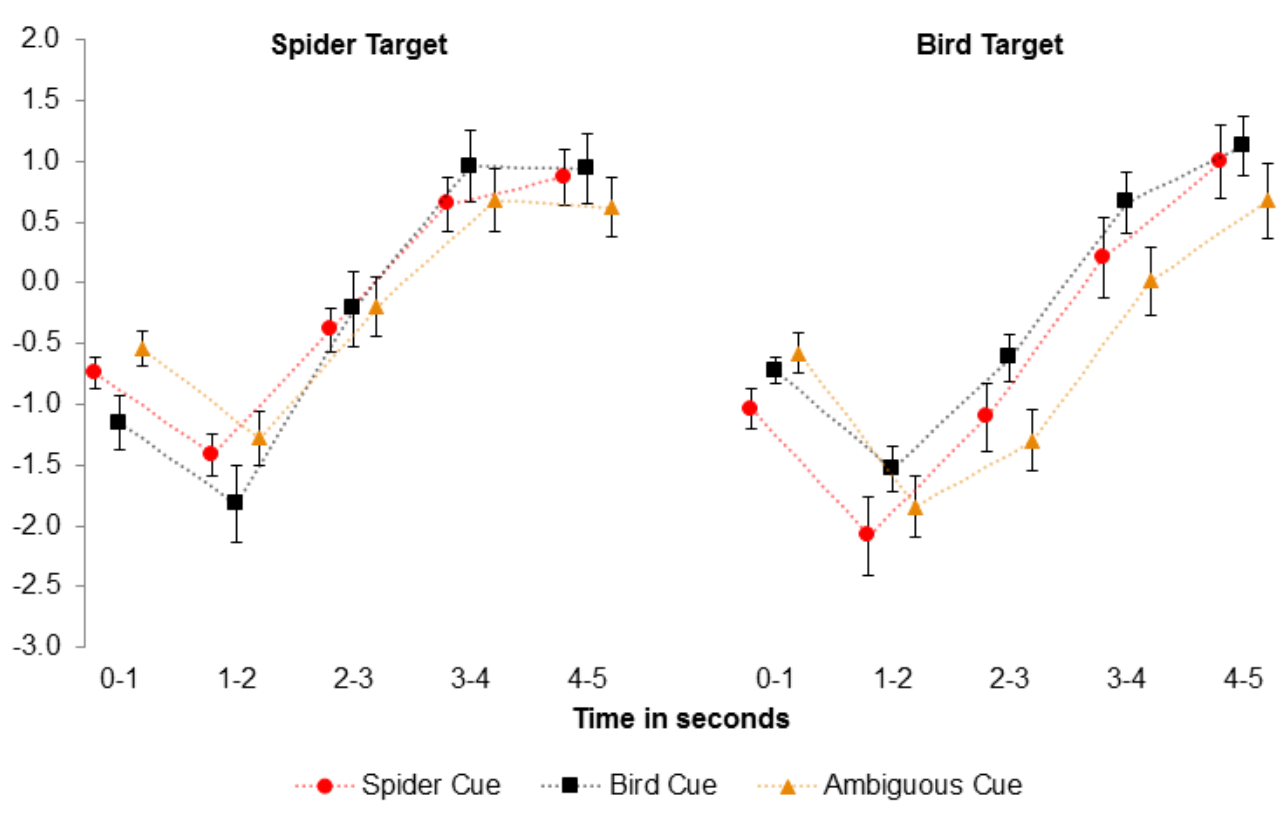


Table 1

Behavior: Summary of invalid responses per group and trial type

\begin{tabular}{|c|c|c|c|c|c|c|}
\hline \multirow[b]{2}{*}{ Trial type } & \multicolumn{3}{|c|}{ Phobics } & \multicolumn{3}{|c|}{ Controls } \\
\hline & Mean & Median & 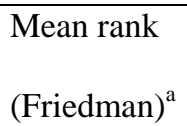 & Mean & Median & $\begin{array}{l}\text { Mean rank } \\
\text { (Friedman) }^{\mathrm{a}}\end{array}$ \\
\hline
\end{tabular}

Number of errors (rate of errors)

Spider target

- $\quad$ Spider cue $(n=68)$

$\begin{array}{llllll}3.6(5.3 \%) & 3.0(4.4 \%) & 2.31 & 5.7(8.5 \%) & 4.0(5.9 \%) & 2.23 \\ 1.0(4.2 \%) & 0.0(0.0 \%) & 1.71 & 2.1(8.7 \%) & 1.5(6.3 \%) & 2.06 \\ 1.2(5.2 \%) & 1.0(4.2 \%) & 1.98 & 1.6(6.8 \%) & 1.0(4.2 \%) & 1.71\end{array}$

Bird target

- $\quad$ Spider cue $(n=24)$

$\begin{array}{llllll}3.8(15.7 \%) & 3.0(12.5 \%) & 1.50 & 3.8(16.0 \%) & 2.0(8.3 \%) & 2.04 \\ 5.1(7.6 \%) & 3.0(4.4 \%) & 1.86 & 7.0(10.4 \%) & 4.0(5.9 \%) & 1.75 \\ 1.7(6.9 \%) & 1.0(4.2 \%) & 1.50 & 3.0(12.7 \%) & 2.0(8.3 \%) & 2.21\end{array}$

All conditions $(n=232)$

$16.4(7.1 \%) \quad 12(5.2 \%)$

$23.4(10.1 \%) \quad 14(6.0 \%)$

Number (rate) of outliers in RT 
Expectancy Influences on Attention to Threat 51

All conditions $(n=232$; $0.7(0.3 \%)$ $0.9(0.4 \%)$

trials without targets being excluded)

$S D=0.84$

$S D=0.88$

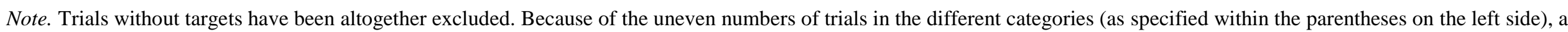

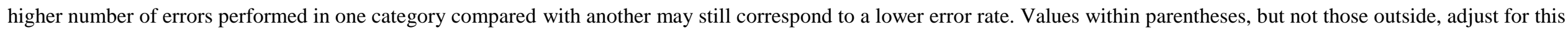
uneven sampling and therefore better correspond to the statistical analyses performed. $\mathrm{RT}=$ reaction time.

${ }^{\text {a }}$ Related to the Friedman tests conducted to test for an influence of expectancy cues on target detection (as revealed in the participants' error rates). 


\section{Table 2}

Summary of conducted ANOVAs

\begin{tabular}{|c|c|c|c|c|c|c|c|c|}
\hline \multirow{3}{*}{ Effects } & \multicolumn{8}{|c|}{ Measures } \\
\hline & \multicolumn{4}{|c|}{ Reaction times } & \multicolumn{4}{|c|}{ Pupil diameter change } \\
\hline & $d f$ & $F$ & $p$ & $\eta_{p}^{2}$ & $d f$ & $F$ & $p$ & $\eta_{\mathrm{p}}^{2}$ \\
\hline Group (1) & 1,43 & 0.06 & .813 & .00 & 1,40 & 5.50 & .024 & .12 \\
\hline Time (2) & & & & & 5,200 & 90.82 & $1.5478 E-49$ & .69 \\
\hline Group $\times$ Time & & & & & 5,200 & 4.39 & .001 & .10 \\
\hline Expectancy (3) & 2,86 & 23.25 & $.8 .4955 \mathrm{E}-9$ & .35 & 2,80 & 3.87 & .025 & .09 \\
\hline Group $\times$ Expectancy & 2,86 & 1.64 & .200 & .04 & 2,80 & 0.68 & .508 & .02 \\
\hline Target (4) & 1,43 & 126.18 & $2.256 \mathrm{E}-14$ & .75 & 1,40 & 0.89 & .352 & .02 \\
\hline Group $\times$ Target & 1,43 & 1.15 & .289 & .03 & 1,40 & 1.00 & .323 & .02 \\
\hline Time $\times$ Expectancy & & & & & 10,400 & 1.11 & .353 & .03 \\
\hline Group $\times$ Time $\times$ Expectancy & & & & & 10,400 & 0.93 & .504 & .02 \\
\hline Time $\times$ Target & & & & & 5,200 & 4.25 & .001 & .10 \\
\hline Group $\times$ Time $\times$ Target & & & & & 5,200 & 1.27 & .279 & .03 \\
\hline Expectancy $\times$ Target & 2,86 & 10.40 & .0001 & .20 & 2,80 & 5.44 & .006 & .12 \\
\hline Group $\times$ Expectancy $\times$ Target & 2,86 & 3.13 & .049 & .07 & 2,80 & 0.01 & .987 & .00 \\
\hline Time $\times$ Expectancy $\times$ Target & & & & & 10,400 & 5.26 & $2.7967 \mathrm{E}-7$ & .12 \\
\hline
\end{tabular}




\begin{tabular}{rrrr}
\hline $1 \times 2 \times 3 \times 4$ & 1.44 & .158 & 100
\end{tabular}

Table 2 continued

\begin{tabular}{|c|c|c|c|c|}
\hline & \multicolumn{4}{|c|}{ Heart rate change } \\
\hline & $d f$ & $F$ & $p$ & $\eta_{p}^{2}$ \\
\hline Group (1) & 1,42 & 0.29 & .591 & .01 \\
\hline Time (2) & 4,168 & 46.31 & 3.4817E-26 & .52 \\
\hline Group $\times$ Time & 4,168 & 0.18 & .948 & .00 \\
\hline Expectancy (3) & 2,84 & 0.82 & .445 & .02 \\
\hline Group $\times$ Expectancy & 2,84 & 0.55 & .577 & .01 \\
\hline Target (4) & 1,42 & 6.00 & .019 & .13 \\
\hline Group $\times$ Target & 1,42 & 6.10 & .018 & .13 \\
\hline Time $\times$ Expectancy & 8,336 & 6.63 & 4.7332E-8 & .14 \\
\hline Group $\times$ Time $\times$ Expectancy & 8,336 & 0.41 & .912 & .01 \\
\hline Time $\times$ Target & 4,168 & 10.53 & $1.2265 \mathrm{E}-7$ & .20 \\
\hline Group $\times$ Time $\times$ Target & 4,168 & 2.12 & .081 & .05 \\
\hline Expectancy $\times$ Target & 2,84 & 1.67 & .194 & .04 \\
\hline Group $\times$ Expectancy $\times$ Target & 2,84 & 0.07 & .934 & .00 \\
\hline
\end{tabular}


Expectancy Influences on Attention to Threat 54

\begin{tabular}{lccccc}
\hline Time $\times$ Expectancy $\times$ Target & $\mathbf{8 , 3 3 6}$ & $\mathbf{2 . 0 9}$ & $\mathbf{. 0 3 6}$ & $\mathbf{. 0 5}$ & .02 \\
$1 \times 2 \times 3 \times 4$ & 8,336 & 0.66 & .727 & .02 \\
\hline
\end{tabular}

Note. $\eta_{\mathrm{p}}^{2}=$ partial $\eta^{2}$. ANOVAs $=$ analyses of variance. Bold font: $p<.05$. 


\section{Table 3}

Pupil diameter: summary of the 2 (Group) $\times 3$ (Expectancy) $\times 2$ (Target) ANOVA results for each time interval

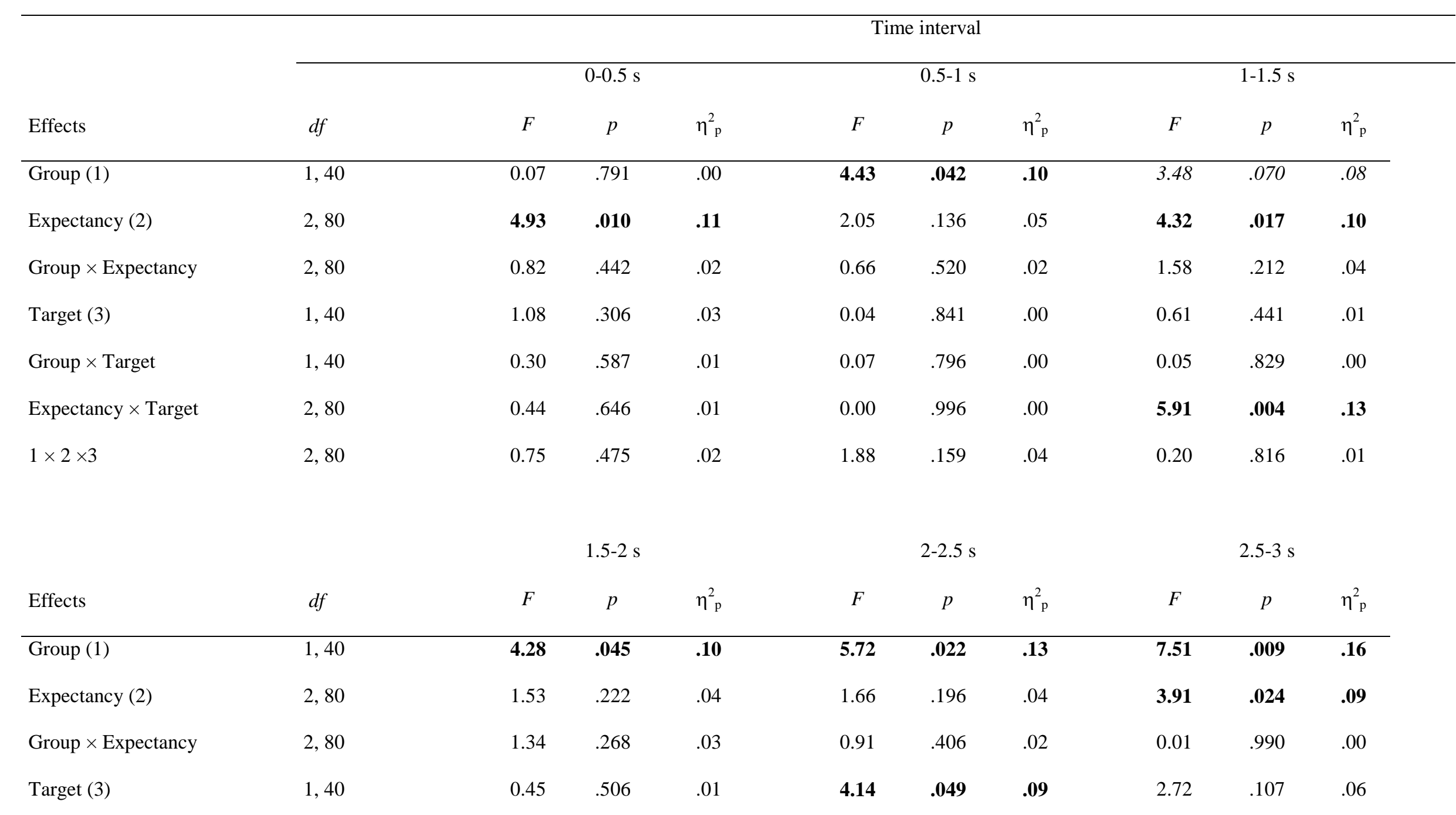


Expectancy Influences on Attention to Threat 56

\begin{tabular}{|c|c|c|c|c|c|c|c|c|c|c|}
\hline Group $\times$ Target & 1,40 & 0.47 & .496 & .01 & 1.76 & .192 & .04 & 1.67 & .204 & .04 \\
\hline Expectancy $\times$ Target & 2,80 & 6.85 & .002 & .15 & 7.52 & .001 & .16 & 4.50 & .014 & .10 \\
\hline $1 \times 2 \times 3$ & 2,80 & 0.34 & .714 & .01 & 0.63 & .536 & .02 & 0.43 & .654 & .01 \\
\hline
\end{tabular}

Note. $\eta_{\mathrm{p}}^{2}=$ partial $\eta^{2}$. Bold font: $p<.05$. 


\section{Table 4}

Heart rate: summary of the 2 (Group) $\times 3$ (Expectancy) $\times 2$ (Target) ANOVA results for each time interval

\begin{tabular}{|c|c|c|c|c|c|c|c|c|c|c|c|c|c|c|c|c|}
\hline \multirow{3}{*}{ Effects } & \multirow[b]{3}{*}{$d f$} & \multicolumn{15}{|c|}{ Time interval } \\
\hline & & \multicolumn{3}{|c|}{$0-1 \mathrm{~s}$} & \multicolumn{3}{|c|}{$1-2 \mathrm{~s}$} & \multicolumn{3}{|c|}{$2-3 \mathrm{~s}$} & \multicolumn{3}{|c|}{$3-4 \mathrm{~s}$} & \multicolumn{3}{|c|}{$4-5 \mathrm{~s}$} \\
\hline & & $F$ & $p$ & $\eta_{\mathrm{p}}^{2}$ & $F$ & $p$ & $\eta_{\mathrm{p}}^{2}$ & $F$ & $p$ & $\eta_{\mathrm{p}}^{2}$ & $F$ & $p$ & $\eta_{\mathrm{p}}^{2}$ & $F$ & $p$ & $\eta_{\mathrm{p}}^{2}$ \\
\hline Group (1) & 1,42 & 0.00 & .998 & .00 & 0.16 & .687 & .00 & 0.87 & .356 & .02 & 0.01 & .913 & .00 & 0.11 & .746 & .00 \\
\hline Expectancy (2) & 2,84 & 4.96 & .009 & .11 & 0.60 & .550 & .01 & 2.69 & .074 & .06 & 3.42 & .037 & .08 & 2.44 & .094 & .05 \\
\hline Group $\times$ Expectancy & 2,84 & 0.09 & .915 & .00 & 0.15 & .859 & .00 & 0.64 & .528 & .02 & 0.80 & .454 & .02 & 0.64 & .531 & .01 \\
\hline Target (3) & 1,42 & 0.13 & .725 & .00 & 3.06 & .087 & .07 & 17.99 & .0001 & .30 & 13.12 & .001 & .24 & 0.73 & .397 & .02 \\
\hline Group $\times$ Target & 1,42 & 0.04 & .847 & .00 & 2.00 & .165 & .05 & 6.79 & .013 & .14 & 6.53 & .014 & .13 & 4.78 & .034 & .10 \\
\hline Expectancy $\times$ Target & 2,84 & 3.47 & .036 & .08 & 3.73 & .028 & .08 & 1.91 & .154 & .04 & 0.46 & .635 & .01 & 0.07 & .936 & .00 \\
\hline $1 \times 2 \times 3$ & 2,84 & 0.37 & .695 & .01 & 0.19 & .831 & .00 & 0.18 & .837 & .00 & 0.22 & .805 & .01 & 0.32 & .728 & .01 \\
\hline
\end{tabular}

Note. $\eta_{\mathrm{p}}^{2}=$ partial $\eta^{2}$. Bold font: $p<.05$. 